NBER WORKING PAPER SERIES

\title{
THE EFFECT OF EMPLOYMENT PROTECTION ON WORKER EFFORT: EVIDENCE FROM PUBLIC SCHOOLING
}

\author{
Brian A. Jacob \\ Working Paper 15655 \\ http://www.nber.org/papers/w15655
NATIONAL BUREAU OF ECONOMIC RESEARCH
1050 Massachusetts Avenue
Cambridge, MA 02138
February 2010

Generous financial support was provided by the William T. Grant Foundation. Thanks to Nancy Slavin, Raquel Saucedo, Art Kim, Joshua Garcia, Lauren McClellan, Amy Nowell, Dan Bugler, Ascencion Juarez and Angela Alonzo at the Chicago Public Schools, and to Tim Daly and Andy Sokatch at The New Teacher Project. Thanks to Elias Walsh, Mimi Engel, Sharon Traiberman and Stephanie Rennane for excellent research assistance. Thanks to Kerwin Charles, John DiNardo, Lars Lefgren, Jonah Rockoff and Ioana Marinescu and seminar participants at the University of Michigan, University of Chicago, University of Wisconsin, Madison and UC Davis for helpful comments and suggestions. Any errors are my own. The views expressed herein are those of the author and do not necessarily reflect the views of the National Bureau of Economic Research.

NBER working papers are circulated for discussion and comment purposes. They have not been peerreviewed or been subject to the review by the NBER Board of Directors that accompanies official NBER publications.

(C) 2010 by Brian A. Jacob. All rights reserved. Short sections of text, not to exceed two paragraphs, may be quoted without explicit permission provided that full credit, including $\odot$ notice, is given to the source. 
The Effect of Employment Protection on Worker Effort: Evidence from Public Schooling Brian A. Jacob

NBER Working Paper No. 15655

January 2010

JEL No. I20,I21,I28,J3,J45,J5,J63

\begin{abstract}
$\underline{\text { ABSTRACT }}$
This paper studies the effect of employment protection on worker productivity and firm output in the context of a public school system. In 2004, the Chicago Public Schools (CPS) and Chicago Teachers Union (CTU) signed a new collective bargaining agreement that gave principals the flexibility to dismiss probationary teachers (defined as those with less than five years of experience) for any reason, and without the elaborate documentation and hearing process typical in many large, urban school districts. Results suggest that the policy reduced annual teacher absences by roughly 10 percent and reduced the prevalence of teachers with 15 or more annual absences by 20 percent. The effects were strongest among teachers in elementary schools and in low-achieving, predominantly African-American high schools, and among teachers with highpredicted absences. There is also evidence that the impact of the policy increased substantially after its first year.
\end{abstract}

Brian A. Jacob

Gerald R. Ford School of Public Policy

University of Michigan

735 South State Street

Ann Arbor, MI 48109

and NBER

bajacob@umich.edu 
"What kind of person could you get to run a small business if you told them that when they came in they couldn't get rid of people that they thought weren't any good?"

Apple Cofounder and CEO Steve Jobs, referring to the importance of staffing in public schools

\section{Introduction}

Economists have long argued that the lack of incentives in most public school systems substantially reduces student performance and increases the cost of education (Hanushek 1994; Hoxby 2003). Teacher employment and compensation policy is one of the most commonly cited instances of weak incentives leading to suboptimal outcomes. As reflected in the quote by Steve Jobs, labor contracts in most public school districts make it extremely difficult for administrators to dismiss teachers for cause. In New York City, for example, only about 50 out of roughly 75,000 teachers were dismissed for performance-related reasons in recent years. ${ }^{1}$

Recent "value-added" studies on teacher effectiveness documenting substantial variation in teacher effectiveness both within and between schools (e.g., Steven G. Rivkin, et al., 2005, Jonah E. Rockoff, 2004) have intensified the scrutiny of teacher hiring, promotion and compensation policies. ${ }^{2}$ Many school districts have begun to experiment with pay-forperformance plans, and there is increasing discussion of ways to change to the teacher tenure system that would provide school administrators with greater flexibility over staffing. The Chancellor of the Washington, D.C. public schools, for example, recently proposed to substitute

\footnotetext{
${ }^{1}$ Personal communication with Jonah Rockoff, February 19, 2008.

${ }^{2}$ In general, variance estimates indicate that a student with a teacher one standard deviation above the mean would score roughly .2 student-level standard deviations higher on standardized math exams. The magnitude of this effect is roughly equivalent to the effect of class size reduction found in the highly acclaimed Tennessee STAR class size reduction experiment, although it should be noted that recent evidence suggests that the impact of having a particularly effective (or ineffective) teacher as measured by value-added fades out considerably within a year or two (see, for example, Jacob et al. Forthcoming).
} 
higher teacher salaries in exchange for a suspension of tenure privileges for one year (Haynes 2008).

And, yet, there is little empirical evidence on whether such incentives will change teacher behavior or improve student achievement. Evidence on merit pay is mixed (Springer and Podgursky 2008, Lavy 2008). There is some evidence that school accountability can improve student achievement, but these policies (including the federal No Child Left Behind program) provide few direct incentives for teachers as they do not change teacher compensation and teachers' job security is still (mostly) guaranteed by collective bargaining agreements. To the best of my knowledge, there is no direct evidence whatsoever on whether policies such as those commonly cited by observers such as Steve Jobs - namely those that reduce employment protections for teachers - will actually improve productivity. Indeed, several recent reports document that existing teacher contracts in many large urban school districts actually provide considerably more flexibility than is commonly believed and yet administrators rarely take advantage of such flexibility (Ballou 2000, Hess and Loup 2008, Price 2009).

In this paper, I take advantage of a unique policy change to examine how the reduction of employment protection for teachers impacts teacher effort and student achievement. In 2004, the Chicago Public Schools (CPS) and Chicago Teachers Union (CTU) signed a new collective bargaining agreement that gave principals the flexibility to dismiss probationary teachers for any reason, and without the documentation and hearing process that is typically required for teacher dismissals. In practice, this dramatically reduced the costs associated with firing young teachers in the district. ${ }^{3}$

\footnotetext{
${ }^{3}$ An informal survey of the 10 largest school districts in the country revealed that principals in these districts do not have the flexibility that Chicago principals were recently granted.
} 
To identify the impact of the policy on teacher effort, I utilize a difference-in-difference estimator that compares changes in teacher absences before and after the policy for probationary versus tenured teachers. As described in more detail below, employee absences have been used in studies of employment protection in other industries, and provide a particularly good proxy for productivity in education. The results suggest that the policy reduced annual teacher absences by roughly 10 percent and reduced the prevalence of teachers with 15 or more annual absences by 20 percent. The effects were strongest among teachers in elementary schools and in lowachieving, predominantly African-American high schools, and among teachers with highpredicted absences.

While student achievement is a more direct measure of teacher productivity, it is not possible to link students to teachers in Chicago over the relevant time period, making it impossible to calculate individual teacher productivity measures. ${ }^{4}$ For this reason, I rely on school-year data to examine the impact of the policy change on student achievement, comparing within-school changes in student achievement over time between schools with higher versus lower fractions of probationary teachers at the time the policy was implemented. ${ }^{5}$ I find some tentative evidence that the policy increased student achievement at the elementary level, although the results are not particularly robust. Additionally, I find that the effects on teacher absences likely explain only a small part of the achievement effects, suggesting that the policy may have impacted teacher behavior in many ways.

\footnotetext{
${ }^{4}$ Moreover, even in the best circumstance, a measure of teacher productivity based on student achievement would not be available for the large fraction of teachers in grades and subjects where students do not take standardized exams.

${ }^{5}$ While average teacher experience in a school is correlated with student achievement and socioeconomic status, I show that there is substantial variation in the fraction of probationary teachers across observationally similar schools. Moreover, by examining within-school changes over time, I can control for any unobservable timeinvariant characteristics of schools that might be associated with initial teacher experience levels and subsequent student achievement (e.g., a particularly dangerous neighborhood, aging school facilities).
} 
This study makes several important contributions. First, it informs the economic literatures on employment protection policies and teacher incentives. To the best of my knowledge, it is one of the few empirical studies of the impact of employment protection on worker effort, and the only study to directly examine this issue in the public sector. By using detailed administrative data that provides employee- and firm-level productivity measures, and exploiting a plausibly exogenous source of variation in employment protection, the analysis here provides among the most compelling evidence on these important issues. Second, the findings presented here have important implications for current education policy debates. Specifically, the decline in teacher absenteeism following the introduction of the policy provides the most compelling evidence to date that changes in teacher contract provisions can improve student achievement.

The remainder of the paper proceeds as follows. Section 2 reviews the prior literature on employment protection and teacher incentives. Section 3 provides background on teacher dismissals in the Chicago Public Schools, and outlines a conceptual framework to help understand the ways in which the policy might influence teacher effort and school productivity. Sections IV and V describe the empirical strategy and data respectively. Section VI presents the results, and Section VII concludes.

\section{Prior Evidence}

The analysis in this paper speaks most directly to the economics literature on employment protection. Most previous research in this area focuses on how employment protection can inhibit a firm from adjusting in response to economic shocks or changes in technology and examines outcomes such as worker mobility and employment levels (Bertola 
1990; Lazear 1990; Hopenhayn and Rogerson 1993). ${ }^{6}$ However, firms may also want to dismiss workers because of poor performance, in which case one would be concerned with the impact of employment protections on worker effort and firm productivity.

Surprisingly few studies have examined the impact of employment protection on worker behavior. In the study most closely related to our analysis, Ichino and Riphahn (2004) use detailed personnel data from an Italian Bank to examine whether worker absenteeism changes after the three-month mark, when bank employees are granted tenure. Looking at changes in absenteeism within employers over time, the authors find that when men get tenure their absence rate more than triples. Interestingly, they find no comparable effect for women.

Martins (2009) examines the impact of legislation that restricted firings for cause in Portugal, using a difference-in-difference approach that exploits the fact that many provisions of the law did not apply to small firms. While he does not find any robust effects on job or worker flows, the author does find that small firms experienced sizeable increases in their performance (as measured by sales per worker) relative to large firms after the introduction of the legislation. The author finds no evidence of either capital deepening or observable changes in worker composition in small firms, leading him to conclude that the effect is driven by increases in worker effort and/or changes in management practices.

Several other studies examine the effects on worker behavior less directly. For example, a related line of research examines the impact of wrongful discharge laws in the United States. ${ }^{7}$

\footnotetext{
${ }^{6}$ While employment protection should unambiguously reduce job flows, in many models the theoretical impact of employment protection on employment levels is ambiguous, as higher firing costs reduce both firing and hiring (Bertola 1992). Recent research using worker- or firm-level data show is mixed, although there is some evidence that commonly adopted employment protection may reduce job mobility and employment (for important recent papers in this literature, see Kugler 1999, Hunt 2000, Bauer et al. 2007, Friesen 2005, Kugler and Pica 2007, Autor et al. 2006, Marinescu 2009).

${ }^{7}$ In a series of more recent papers, Autor et al. (2004, 2006 and 2007) reconcile the conflicting findings from prior research and find evidence that one wrongful-discharge provision (i.e., the implied-contract exception) reduced
} 
Using the variation in dismissal costs generated by the adoption of wrongful-discharge protection by state courts, Autor et al. (2007) find that one of three main wrongful-discharge provisions, the good-faith exception, seems to decrease total factor productivity. However, the authors caution that this result is not particularly robust, in part because the good-faith exception does not seem to impact employment or wages. Indeed, the one provision that the authors find does impact employment, the implied-contract exception, does not seem to impact productivity. ${ }^{8}$

This paper also speaks to the growing literature on teacher incentives, a line of research that fits within the broader work on employee incentives within the personnel economics literature (see Pendergast 1999 for a review of the literature on employee incentives). Research on teacher incentives has focused on two types of policies that arguably provide enhanced incentives for teacher performance: merit pay or other compensation schemes that link pay to student performance, and school accountability policies that tie rewards or sanctions to student performance. Two recent reviews of pay-for-performance in education conclude that the existing evidence on merit pay is limited and shows mixed results (Springer and Podgursky 2008, Lavy 2008). There is some compelling evidence that well-structured teacher incentives can substantially improve student performance, but this research comes from developing countries like Kenya and India and may not generalize well to schooling in developed countries. ${ }^{9}$

employment rates, but that the two other major provisions (i.e., the public-policy and good-faith exceptions) had no robust employment or wage effects.

${ }^{8}$ Using similar variation as Autor et al. (2006), Bird and Knopf (2009) find that wrongful discharge protections increased labor expenses and reduced profitability in the commercial banking sector and Petrin and Sivadasan (2006) find that employment protection increased the gap between marginal revenue product and wages. Besley and Burgess (2004) find that Indian states that reformed laws in a pro-worker direction experienced lower output, employment, investment and productivity in the formal sector, as Ill as an increase in urban poverty.

${ }^{9}$ While pay-for-performance has been around for many years in public education, it has received increasing attention in recent years. This has led to a dramatic increase in the number of districts experimenting with some form of merit pay, and to more research on the impact of such policies. Several ongoing studies, including a random assignment evaluation in Nashville, TN, promise to shed more light on the prospects for merit pay in education. 
In the area of school accountability, some evidence suggests that policies that link consequential sanctions to student performance do improve student achievement, particularly in math (Jacob 2005, Hanushek and Raymond 2005). Similarly, Dee and Jacob (2009) find that the federal No Child Left Behind legislation increased math performance. On the other hand, there is evidence that such accountability policies often lead to unintended, negative consequences (Jacob 2005, Figlio and Winick 2005, Neal and Schanzenbach 2009). Furthermore, school accountability policies, including the federal No Child Left Behind Act, provide no direct incentives for teachers and thus do not provide a compelling test of the type of employment protection policies studied here.

Finally, a recent paper provides evidence that teachers respond to the implicit incentives generated by career concerns. Using data on public school teachers in North Carolina, Hansen (2009a) finds that teacher absences are positively correlated with both experience and tenure in a particular school, and absences increase dramatically in the year prior teacher retirement or departure. While this study sheds light on teacher incentives broadly, it does not speak directly to the potential impact of a change in teacher tenure policy.

\section{Background}

\subsection{Teacher Dismissal Policy in the Chicago Public Schools}

As in many public school districts, teacher layoffs and dismissals in the Chicago Public Schools are highly regulated. In situations where teacher positions must be eliminated due to enrollment changes or a budget shortfall, the collective bargaining agreement outlines a 
procedure by which the least experienced teachers are let go first. This is typically known as a reduction-in-force (RIF).

In the past, it has been extremely difficult for principals to dismiss teachers outside the auspices of a RIF. Like most other districts, the collective bargaining agreement in Chicago provides considerable protection for tenured teachers that make it very time-consuming and difficult for principals to dismiss these teachers for cause. Unlike many smaller, suburban districts in Illinois, however, the collective bargaining agreement in Chicago also made it very difficult for principals to dismiss non-tenured teachers. Perhaps for this reason, formal principal evaluations in Chicago are remarkably generous. In 2007, for example, only 15 out of the 11,621 teachers who were evaluated in 2007 received a rating of unsatisfactory, and only 641 out of 11,621 (roughly 5.5 percent) received a rating of satisfactory. The remaining teachers were rated excellent or superior.

The adoption of a new collective bargaining agreement on July 1, 2004 made substantial changes to the tenure system in Chicago that, for the first time in the 2004-05 school year, provided principals with the ability to easily dismiss non-tenured teachers. So, in the analysis that follows, the academic years 2001-02 through 2003-04 constitute the "pre-policy" period and the academic years 2004-05 through 2006-07 constitute the "post-policy" period. The July 2004 contract created a new three-tiered classification system for Chicago teachers: (1) Temporarily Assigned Teachers (TATs) include individuals who are in a temporary placement (such as a long-term substitute who is filling in for a teacher on leave) and are not earning tenure; (2) Probationary Appointed Teachers (PATs) include individuals who have been regularly appointed to a position but have been teaching for fewer than five consecutive years (i.e., during this period, Chicago teachers received tenure after four years of service) and; (3) tenured teachers. 
Non-renewal works in the following way. Each February, principals are able to log into a district computer system that has a list of all of the PATs in their school. The principal can then check one of two boxes: renew or non-renew. ${ }^{10}$ The administrative ease with which administrators can dismiss a probationary teacher - with a simple "click" of a button - is noteworthy. In essence, the collective bargaining agreement adopted in July 2004 dramatically reduced the costs of firing a probationary teacher in the district. This policy change made Chicago the only large, public school district in the country to provide principals with this type of flexibility over personnel decisions. ${ }^{11}$

Teachers are notified by formal letter of non-renewal sometime in late April or early May. If a principal chooses to non-renew a teacher, the teacher is guaranteed health benefits through August $31^{\text {st }}$ of the current year, and is allowed to reapply to positions in other Chicago public schools. Moreover, the teacher is eligible for unemployment benefits as non-renewal is viewed as a layoff rather than a dismissal for cause. ${ }^{12}$ However, non-renewed teachers are not guaranteed another job in the CPS. ${ }^{13}$ Although principals are required to provide district

\footnotetext{
${ }^{10}$ If the principal checks the "non-renewal" box, he or she must check indicate at least one of the following five reasons for the non-renewal: deficiencies with instruction (e.g., planning, methods, subject matter knowledge), deficiencies with environment (e.g., classroom management, teacher-pupil relationships), deficiencies with professional and personal responsibilities (e.g., attendance, tardiness, professional judgment), deficiencies with communication (e.g., parent conference skills, relations with staff), or deficiencies with attitude (e.g., lack of cooperation, lack of respect for others).

${ }^{11}$ Principals are not required to make any decision for a particular teacher. If a principal either chooses to renew a PAT or takes no action, then the teacher is still eligible to be laid off through the standard RIF process.

${ }^{12}$ PATs who are rehired by November $1^{\text {st }}$ will not experience a break in service for tenure purposes.

${ }^{13}$ PATs who are displaced through the standard RIF process are also guaranteed health benefits through August $31^{\text {st }}$ and eligible for unemployment insurance. However, they are also guaranteed a position as a cadre teacher, which means that they are guaranteed work as a substitute every day and receive a higher rate of pay and better benefits than a day-to-day substitute. In contrast, non-renewed teachers have to apply to be a cadre teacher, and are accepted on a case-by-case basis after displaced PATs. Tenured teachers who are displaced through the RIF process receive even more benefits. Personal communication with Nancy Slavin, Director of Teacher Recruitment, Chicago Public Schools, June 22, 2007.
} 
officials with at least one reason for the non-renewal decision, they are not required to justify or explain their decision and they do not need to provide teachers with this reason. ${ }^{14}$

\subsection{Conceptual Framework}

A simple economic model suggests that the reduction in firing costs could influence worker effort and productivity ${ }^{15}$ in one of two primary ways: by changing the behavior of existing workers and/or by changing the composition of workers in the firm. For many workers, lower firing costs will induce greater effort by creating a stronger link between job performance and continued employment. Lower firing costs could also change the composition of workers in the firm. If the effort required to avoid dismissal is sufficiently costly for a particular employee, for example, the policy might induce her to quit. Perhaps more importantly, the reduction in firing costs will likely lead the firm to dismiss a larger fraction of workers.

The impact of such compositional changes on worker productivity depends on a variety of factors including the principal preferences (e.g., the type of teacher the principal chooses to dismiss and the type hired as the replacement) and the elasticity of supply for teacher quality. ${ }^{16}$ If teachers dismiss probationary teachers with below average productivity, supply is relatively inelastic, and principals do not change their hiring behavior, then one would expect the average productivity in the school to rise over time. $^{17}$

\footnotetext{
${ }^{14}$ If a principal chooses to non-renew a PAT in his or her fourth year (that is, immediately prior to tenure), the principal is required to inform the teacher which reason(s) were listed, but is not required to further justify or explain the decision.

${ }^{15}$ I use the term effort and productivity interchangeably in this discussion.

${ }^{16}$ In other work, I estimate the relative weight that school administrators place on a variety of teacher characteristics in making dismissal decisions (Jacob 2009). I find principals are significantly more likely to dismiss teachers who are frequently absent, have received poor evaluations in the past and are less effective at raising student achievement, all of which suggests potential composition effects.

${ }^{17}$ The policy might also impact worker productivity by altering hiring practices in other ways. The ability to easily dismiss probationary teachers essentially decreases the cost of hiring a new teacher if one considers the expected difficulty of dismissing an ineffective teacher as part of the cost. All else equal, this will increase a principal's
} 
There are several other potential channels through which a reduction in firing costs among a subset of teacher might influence teacher productivity. First, the policy might also operate through spillovers from probationary to tenured teachers. To the extent that there are substantial complementarities across teachers within the same school, the policy might increase the productivity of tenured teachers who were not directly affected by the renewal policy. If, for example, the three $5^{\text {th }}$ grade teachers in a particular school work together to plan activities, greater effort and commitment on the part of the one probationary teacher could benefit the two tenured teachers (Jackson and Bruegmann 2009). ${ }^{18}$

Second, the reduction in firing costs may lead to a change in management practices (Martins 2009). For example, the policy may induce school principals to adjust aspects of the school organization, curriculum or pedagogy. Based on my informal interviews with several principals and discussions with central office personnel, this does not appear to have occurred much, if at all. Finally, the policy could impact productivity by influencing teacher supply more generally. The introduction of the renewal policy increased the risk associated with a new teaching position in the CPS. In the absence of any increase in financial compensation, the policy will make teaching positions in the CPS less attractive for risk-averse individuals, which

\footnotetext{
likelihood of hiring a "higher-risk" teacher - that is, a teacher about whom the principal has less information with regard to job performance. For example, the introduction of the renewal policy might make principals more inclined to hire teachers with alternative certification, or individuals entering teaching as a second career. Assuming that principals are risk-averse in their hiring practices, this might increase the overall productivity of the teacher workforce. Moreover, to the extent that principals differ in their ability to identify effective teachers (pre- or posthire), this policy might exacerbate across-school differences in teacher quality.

${ }^{18}$ Autor (2003) notes that employment protection policies may reduce the incentive of employees to invest in firmspecific skills, which could lower productivity.
} 
will tend to shift the supply curve inward. ${ }^{19}$ In practice, however, this does not seem to have happened in Chicago. ${ }^{20}$

\subsection{Some Basic Facts about Teacher Dismissals}

Table 1 provides summary statistics on the prevalence of teacher dismissal under this new policy. Several interesting facts stand out. First, while roughly $10-13$ percent of probationary teachers were dismissed each year under the new policy, 30-40 of schools did not dismiss any teachers. This did not change dramatically between 2005 and 2007. Younger probationary teachers were substantially more likely to be dismissed than others, consistent with the idea that principals learn the most about a new teacher in his or her first year.

While there was a positive correlation between low student performance and the prevalence of teacher dismissal in a school, it was not merely high-performing schools that failed to dismiss any of their teachers. In 2005, 65 percent of schools in the lowest quartile of student achievement in the district dismissed at least one teacher compared with 46 percent of the highest-achieving schools in the district. Splits using school value-added measures yield comparable results.

In other work, I show that once one controls for teacher background characteristics, factors such as school achievement level and racial composition of the school are not correlated with the school's dismissal rate (Jacob 2007). Indeed, a rich set of observable teacher, school

\footnotetext{
${ }^{19}$ Note that this could influence teacher supply decisions with regard to accepting a position in the CPS initially as well as continuing to teach in the CPS in subsequent years.

${ }^{20}$ Based on my conversations with district officials and a review of teacher application files over this period, it appears that neither the number of applicants per available position nor the observable characteristics of applicants changed noticeably after the introduction of the policy. Moreover, the number of voluntary exits among new teachers has not increased in recent years, although this statistic may be misleading if, prior to the policy, a larger fraction of the officially voluntary exits were actually "encouraged" on the part of school administrators. Unfortunately, there is no way to distinguish truly voluntary versus involuntary exits prior to the introduction of the policy.
} 
and principal characteristics explain less than 10 percent of the variation in teacher dismissal under the new policy. This suggests that there was considerable variation across principals in the willingness to utilize this particular policy lever.

Finally, it is worth noting that in any given year, over half of the dismissed teachers were rehired the following year by another school in the district. For example, $50.6 \%$ of first-year probationary teachers who were dismissed in Spring 2005 were rehired by a CPS school in Fall 2005. Among third- and fourth-year probationary teachers who were dismissed, the rate was over $60 \%$. Given the fact that at least some of the dismissals under the policy were the result of position cuts, in which case the teacher's former principal may have provided the teacher with a good recommendation, it is not surprising that some fraction of dismissed teachers were rehired. However, it is also likely that some fraction of teachers dismissed due to poor performance were also rehired by other CPS schools. It is not clear why principals would rehire teachers who had been dismissed from a different school for performance reasons. Non-renewal decisions are not made public to all principals in the district, but a hiring principal could almost certainly get this information by contacting the candidate's former principal.

These statistics seem to suggest that the introduction of the dismissal policy had a large impact on job separations in the district. However, the numbers of teachers who were nonrenewed in any given year likely overstates the impact of the policy because a number of young teachers would likely have left the CPS in the absence of the policy, either voluntarily or due to subtle "encouragement" on the part of the principals. If the dismissal policy merely formalized previously informal dismissals, then one would not necessarily expect to find a substantial change in separations. Even in this case, however, the policy may have influenced teacher productivity if it changed the expectation or transparency of the dismissal process. 
To shed light on these issues, Table 2 presents statistics on teacher mobility before and after the implementation of the non-renewal policy. In the years prior to the introduction of the policy, roughly 10-15 percent of first-year teachers probationary teachers left the CPS and an additional 4 percent moved to a different CPS school. In the years after the policy, the corresponding rates were roughly 18 and 10 percent respectively. Comparing the year immediately prior to the policy (2004) with the first two years of the policy (2005 and 2006), the separation rate increased by roughly 9 percentage points (10 percent) in years immediately following the policy. In contrast, there was virtually no change among more experienced teachers (i.e., those with 6-15 years of experience) who were not subject to the policy. ${ }^{21}$ In summary, the dismissal policy appears to have had at least a modest impact on teacher separations, although the impact is not as large as the overall nonrenewal numbers would suggest. $^{22}$

\section{Empirical Strategy}

To estimate the impact of the policy on teacher productivity, I utilize a simple differencein-difference (DD) estimator that compares changes in absence rates between teachers who were subject to the policy and those who were not. The control group in the baseline analysis consists of all tenured teachers, although I later show that our results are robust to other plausible control

\footnotetext{
${ }^{21}$ Interestingly, I see a quite different pattern among temporary teachers. The separation rates for this group appears to have decreased following the introduction of the policy. It is not clear what might explain this pattern among temporary teachers, except that perhaps principals may have kept temporary teachers in part to replace the probationary teachers that they were able to dismiss.

${ }_{22}$ An alternate strategy for estimating the fraction of dismissed teachers who would not have left voluntarily is to compare the separation rates of renewed vs. non-renewed teachers under the new policy. Among those first-year teachers in 2004-05 who were renewed, only 89 percent were teaching in the CPS in the following year (and 11 percent left voluntarily). In comparison, 56 percent of first-year teachers who were not renewed in 2004-05 ended up teaching in the CPS in the following year. Assuming that 11 percent of the non-renewed teachers would have left voluntarily as was the case with the renewed teachers, I can calculate that 75 percent $[(.44-.11) /(.44)=.75]$ of the separations among non-renewed teachers were involuntary; or rather, would not have occurred in the absence of the policy.
} 
groups (e.g., only young, tenured teachers). I include both probationary and temporary teachers as treatment groups. As described above, probationary teachers were directly affected by the policy. Temporary teachers include individuals who are not fully credentialed and were (in theory) easier to dismiss even before the introduction of the new policy. Under the new policy, they are first in line for layoffs and easier to dismiss than PATs or tenured teachers. Given that most temporary teachers hope to become probationary teachers, it seems likely that the dismissal policy may have influenced their behavior as well. For this reason, I include temporary teachers in our analysis but allow the policy to have a differential impact on this group relative to probationary teachers.

For the baseline specification, I estimate the following regression via OLS:

$$
\begin{aligned}
A_{\text {iset }}= & \beta_{0}+\beta_{1} P A T_{\text {iset }}+\beta_{2} T A T_{\text {iset }}+\beta_{3} \text { post }_{t}+\beta_{4}\left(\text { post }_{t} * P A T_{\text {iset }}\right)+\beta_{5}\left(\text { post }_{t} * T A T_{\text {iset }}\right)+ \\
& \operatorname{Exp}_{e}+X_{i}+Z_{s t}+\delta_{t}+\lambda_{s}+\varepsilon_{\text {iset }}
\end{aligned}
$$

where $A_{i s e t}$, refers to the number of absences of teacher $i$ in school $s$ with experience $e$ (e.g., firstyear teacher, second-year teacher, etc.) in year $t$. As described below, the data includes information on teachers from 2003-04 through 2006-07. The variable post is an indicator that takes on the value of one in years following the introduction of the policy (i.e., 2005-2007). The variables $P A T$ and $T A T$ are binary indicators for probationary and temporary teachers respectively. Tenured teachers are the omitted category. Note that these job status variables are time varying indicators so, for example, an individual teacher may appear as a PAT in one year and a tenured teacher in subsequent years. ${ }^{23}$

\footnotetext{
${ }^{23}$ One might be concerned about including probationary teachers who became tenured under the new policy. By definition, these teachers were not dismissed, and thus presumably have higher productivity than the average teacher from the same cohort. By including the post-tenure observations for these "survivors" in the analysis, one may be inflating the productivity of the control group in later years. I later show that, in practice, the exclusion of these teacher-year observations does not substantially change our estimates. Hence, for simplicity, I include them in the baseline specification.
} 
In all models, I also include time (i.e., academic year) fixed effects denoted by $\gamma_{t}$, school fixed effects denoted by $\lambda_{s}$, and a full set of teacher experience indicators denoted by $\operatorname{Exp}$. In some specifications, I also include teacher characteristics $(X)$ and school-year characteristics $(Z)$ as well. In equation (1), the coefficients on the interaction between PAT/TAT and post, $\beta_{4}$ and $\beta_{5}$, measure the net effect of the policy.

As noted above, the policy can operate through both incentive and compositional effects. Ideally, one would like to be able to separate these components. One potential approach is to focus on within-teacher variation by estimating a variant of equation (1) that includes teacher fixed effects. ${ }^{24}$ While this approach will eliminate any compositional effects, it will only identify the policy impact for a select group of teachers. Specifically, the teacher fixed effect model will not capture the policy effect for teachers hired in 2005 or later because, by construction, I will not observe these teachers under both regimes. If there were homogeneous incentive effects, this would not be a problem. But if the incentive effects of the policy were largest on these young, newly hired teachers, which seems likely, then the estimates from a teacher fixed effect model could be a misleading estimate of the average treatment effect.

More generally, if the incentive effects vary by calendar year and/or experience level, it will not be possible to cleanly separate the incentive and composition effects. Unfortunately, this also seems quite likely to be the case. For example, incentive effects may have been larger after the first year of the policy, when teachers realized that there was a non-trivial chance of being dismissed. Similarly, incentive effects may have been smaller for teachers who had "survived" dismissal in prior years. I present effects separately by the calendar year and a teacher's risk

\footnotetext{
${ }^{24}$ In addition to focusing exclusively on the incentive effects, this approach allows one to rule out potential confounders related to composition changes such as an unrelated influx of high quality individuals from other occupations spurred by a weak local economy.
} 
year (defined below), which shed some light on incentive and composition effects even if they do not perfectly distinguish the two.

\section{Data}

The data for this study comes from several sources. Teacher personnel files provide information on teacher background, current assignment and renewal decisions. I supplement this teacher-level data with information on school demographics, principal characteristics from personnel files, and student test score information.

\subsection{Determining job status}

To determine a teacher's job status, I rely on administrative teacher assignment data provided by the CPS. Starting in 2004-05, district files clearly identify whether a teacher is a temporary, probationary or tenured teacher. In earlier years, temporary teachers are clearly identified but the district did not utilize a comparable classification system for teachers for other teachers, so I determine job status using other information. During the Spring/Summer of 2004, the district conducted a thorough audit of all teachers in the system to determine which were to be assigned probationary status for the 2004-05 school year. In doing so, this data provides a teacher's status in 2003-04. For teachers who were teaching in the district in 2003-04 (or later years), I use their later job status to impute their job status as of 2002-03. For example, if an individual was a second year probationary teacher in 2003-04, I consider them a first year probationary teacher in 2002-03. If a teacher were tenured in 2003-04, then I assume that they were also tenured in 2002-03 if they also had at least 5 years of experience as of 2002-03. If the teacher had fewer than 5 years of experience in 2002-03, I consider this teacher probationary. 
For teachers who left the system after 2002-03, I utilize a combination of experience and assignment to determine job status. Specifically, if the individual had at least 5 years of experience and was assigned to a position (as opposed to filling the position of another teacher on leave, for example), then I consider the individual to be tenured. While this process is necessarily imperfect, I believe that it is accurate for the vast majority of teachers and any remaining measurement error should simply lead to attenuation of the policy effect.

There is one final complication regarding job status that is worth noting. Before the introduction of the non-renewal policy, there was a category of teachers who were fully credentialed, but not formally appointed to a position (i.e., not on the "tenure track"). These unassigned teachers composed roughly one-quarter of all probationary teachers in 2003-04. When the policy was implemented in 2004-05, all of these previously "unassigned" teachers were formally appointed. At this point, they became first-year probationary teachers regardless of the number of years they had been working as in the CPS. Hence, there is a wide range of experience among PATs (as with TATs and tenured teachers). While these teachers were similar to the appointed, non-tenured teachers prior to the introduction of the new policy in the sense that both were, in theory, more easily dismissed than their tenured colleagues, there were also important differences between the two groups. In practice, assigned teachers had more job security than their unassigned colleagues. I include both unassigned and assigned teachers in the baseline specifications (along with a full set of experience controls), and later present estimates that focus on each group individually. 


\subsection{Measures of teacher productivity}

Teacher absence data from payroll records serve as our primary measure of teacher productivity. This measure is appealing for several reasons. First, absences are measured extremely well in the payroll data and they are easily interpretable. Second, teacher absences impose substantial financial costs on the district, which has to pay for substitute teachers, as well as non-pecuniary costs on school administrators and other teachers who must juggle schedules to accommodate an absent colleague. Third, several recent studies have documented that teacher absences have a strong, negative association with student achievement, providing evidence that this association is causal (Clotfelter et al. 2007, Miller et al. 2007). ${ }^{25}$ Indeed, in other work using Chicago data from a similar time period, I show that a teacher's absences are negatively associated with principal evaluations of the teacher and with a teacher's value-added contribution to student achievement (Jacob and Walsh 2009). Finally, there is considerable evidence that absences are at least partly discretionary. Research suggests that teacher absences are more frequent on Mondays and Fridays (ERS 1980), higher among temporary teachers and correlated with more general shirking in the workplace (Bradley et al. 2007) and negatively associated with buy-back provisions that allow teachers to receive payment for unused absences (Ehrenberg et al. 1991). Hansen (2009a) finds that teacher absences in NC correspond to experience, tenure in a school, the presence of a new principal and proximity to retirement in ways that would suggest absences are a good proxy for discretionary effort.

\footnotetext{
${ }^{25}$ Using North Carolina data, Clotfelter et al. (2007) employ teacher fixed effects and find that each 10 days of teacher absences decrease student achievement by 2.6 percent of a standard deviation. Miller et al. (2007, forthcoming) focus on one disadvantaged urban district and also use teacher fixed effects. They find that each 10 days of teacher absences reduce students' mathematics achievement by 3.3 percent of a standard deviation. In the context of a developing economy, Duflo and Hanna (2006) provide experimental evidence that teacher absences reduce student performance.
} 
Teachers in Chicago are allotted 10-12 paid sick or personal days per year. Teachers can accumulate unused sick days across years, up to a maximum of 315 days. These days can be cashed in upon leaving the district at a rate of $100 \%$ for those teachers retiring with at least 40 years of experience and at a 90\% rate for teachers with 20-40 years of experience. In addition, teachers get 3 personal days per year, which can be used for emergencies, religious holidays or personal business. There are some restrictions regarding the use of personal days (e.g., teachers cannot use all three days in succession and they cannot be used in the first or last week of school, or on a day before or after a holiday), although unused personal days get banked as sick days. ${ }^{26}$

The primary outcome measure is simply the total number of days that each teacher was absent during the academic year, which generally runs from the beginning of September through mid-June, excluding "excused absences" for professional development or other sanctioned activities. ${ }^{27}$ I also present results using indicators for frequent and/or inappropriate absences as the outcome (e.g., indicator for 15+ absences during the year, number of absences on Fridays, or fraction of total absences on Mondays or Fridays, etc.).

Table 3 presents summary statistics on the final sample of 33,600 teachers over 5 years (117,420 teacher-year observations). Looking down column 1 , one sees that roughly 77 percent of teachers are women, 48 percent are white, 35 percent are Black and 14 percent are Hispanic. The average age is 44 years, but 25 percent of teachers are less than 33 years old. Over 50 percent of teachers received a BA in education, and 16 percent of teachers in the sample had

\footnotetext{
${ }^{26}$ Information on teacher absence policy comes from a review of the recent CPS teacher collective bargaining agreements. Teachers with $13+$ years of experience are entitled to 11 paid sick/personal days per year and (as of 2008) teachers with $18+$ years of experience are entitled to 12 paid days. Starting in 2009, teachers were allowed to accumulate up to 320 days of sick leave across years. Teachers who retire at age 65 or older they would get to cash in $85 \%$ of their sick days. Teachers who retire before 65 years of age with less than 20 years of experience cannot cash in any of their sick days. For leaves due to illness over 10 days, teachers must apply for a personal illness leave.

${ }^{27}$ Unfortunately, I do not have additional detail such as whether the teacher notified the principal ahead of time, or simply did not show up in school.
} 
failed at least one certification exam in the past, and 28 percent had never passed a certification exam. ${ }^{28}$ Columns 2-7 present statistics separately for temporary, probationary and tenured teachers in pre- and post-reform years. Prior to the introduction of the dismissal policy, the average number of absences was roughly comparable across groups, although a slightly higher fraction of temporary teachers had at least 15 absences per year. Most interestingly, one sees that the number of absences drop by over 1 day per year (roughly 12 percent) for temporary and probationary teachers, but decrease by less than half that amount among tenured teachers. These descriptive statistics thus provide the first indication that the new dismissal policy may have impacted teacher effort.

\section{Results}

I begin by showing the unadjusted trends of teacher absences by job status. Figure 1a shows the trends in absences from 2003 through 2007 separately for tenured and untenured teachers. The two groups appear to have roughly comparable absence rates in 2003 and 2004, with the average teacher being absent a little more than 8 times during a year. Starting in 2005, absences within both groups decline, but the change is noticeably larger among untenured teachers. Trends in the fraction of "high-absence teachers" (i.e., teachers who are absent at least 15 times during a year), shown in Figure 1b, tell a similar story. Figures 2 and 3 present the analogous trends for elementary and high school teachers respectively. In general, the patterns are similar, though it appears that the impact of the dismissal policy was somewhat larger among elementary school teachers.

\footnotetext{
${ }^{28}$ The group that has never passed a certification exam mainly includes older teachers who were grandfathered into the existing certification regime.
} 
Table 4 presents baseline results from equation (1), which includes school, calendar year and experience year fixed effects. Standard errors are clustered by school. The results shown in column 1 imply that the dismissal policy reduced absences among probationary (temporary) teachers by roughly $.71(.95)$, which corresponds to a reduction of roughly $8-10$ percent of the pre-reform mean. ${ }^{29}$

Columns 2-4 show estimates for several other potentially interesting absence measures. In order to measure the impact of the policy on the incidence of serious shirking, column 2 focuses on the likelihood that a teacher was absent at least 15 days in the year, which corresponds with the $75^{\text {th }}$ percentile of the absence distribution. Results are comparable using $10+$ and $20+$ absences. The estimates suggest that the policy reduced the incidence of such frequent absences by 2.2 percentage points ( 16 percent) and 4.9 percentage points ( 30 percent) among probationary and temporary teachers respectively. Because prior literature has suggested that Friday absences are more indicative of shirking than absences on other days, columns 3 and 4 focus exclusively on Friday absences. The results are largely the same.

While the point estimates for temporary teachers are slightly larger than those for probationary teachers, in all but one outcome $(15+$ absences), the effects on the two groups are not statistically different. Hence, for the sake of parsimony, subsequent tables present results that combine probationary and temporary teachers. Columns 5-8 show these baseline estimates for all untenured teachers (i.e., probationary and temporary) combined.

\subsection{Sensitivity analyses}

The results shown above suggest that the introduction of the dismissal policy led to a modest reduction in teacher absences. However, this inference depends on a variety of

\footnotetext{
${ }^{29}$ This is equivalent to an effect size of roughly the same size.
} 
assumptions. Perhaps most importantly, I assume that there were no other explicit policies or other unobserved factors that would have affected tenured and untenured teachers differentially starting in 2005. In the context of the Chicago policy, one might be particularly concerned about factors that were changing either the composition or incentives of new/younger teachers in Chicago.

Based on a review of CPS policies during this time and informal conversations with district administrators, it does not appear that there were any other programs that one would have expected to influence outcomes such as teacher absenteeism differentially by job status (though there were clearly a number of policies aimed at reforming low-performing schools, particularly at the secondary level). While it is not possible to reliably judge prior trends based only two years of data, Figures 1-3 do not reveal any substantial differences between probationary and tenured teachers in the levels or changes in absences.

In addition, a particular feature of the policy implementation provides a further test of this assumption. As described in the data section, before the introduction of the non-renewal policy, there was a category of teachers who were fully credentialed, but not formally appointed to a position (i.e., not on the "tenure track"). When the policy was implemented in 2004-05, all of these teachers were formally appointed and became first-year probationary teachers regardless of the number of years they had been working in the CPS. This effectively breaks the link between teacher experience and probationary status, allowing one to assess whether the purported policy effects are driven simply by changes among novice teachers. ${ }^{30}$

\footnotetext{
${ }^{30}$ Even in the absence of this feature, there would have been some variation between teacher experience and job status because the experience variables in the CPS files correspond with when the teacher began working in the district in any capacity. A non-trivial fraction of teachers start in temporary or non-teaching positions, and then transition into standard teacher roles. In addition, some teachers that transfer from other districts can start in a higher job status.
} 
Figures $4 \mathrm{a}$ and $4 \mathrm{~b}$ show the trends in absences separately for teachers less than five years of experience (tenure is earned after four years of service) and teachers with five or more years of service (using the same samples as in Figures 1a and 1b). If one thought that unobserved prior trends or concurrent policies most relevant for younger teachers were driving the apparent policy impact, then one would expect the trends in Figure 4 to resemble those in Figure 1. However, the new figures show a very different picture. Comparing the older versus younger teachers, I see that the novice group has substantially fewer absences than more experienced teachers in all years but the trends among the groups are nearly identical. This suggests that the results above are not simply an artifact of some other unobserved phenomenon that disproportionately influenced novice teachers in Chicago over this period. Column 9 in Table 4 shows estimates that mirror Figures $4 \mathrm{a}$ - namely, our baseline specification but where the treatment group is defined as teachers with less than five years of experience. Consistent with Figure 4a, there is no treatment effect in this specification. Figures 5 and 6 present comparable trends separately for elementary and high schools, revealing a similar pattern across the grade levels.

The model also assumes that the policy was unanticipated. If teachers were aware of the impending changes during 2003-04, for example, then they may have altered their behavior in ways that would bias the estimate (e.g., young teachers may have worked harder in an effort to avoid dismissal in the following years, which would lead one to underestimate any productivity improvements). My conversations with district administrators responsible for negotiating the new collective bargaining agreement in 2004 suggest that neither teachers nor administrators were aware of this policy until close to the time of ratification in July 2004.

A common concern in this type of analysis involves selective attrition. For example, one might be concerned that the introduction of the policy led certain teachers to leave the system, or 
discouraged other teachers from accepting jobs in the CPS. In this context, however, attrition should be considered a legitimate compositional effect of the policy. As discussed above, while it is quite difficult to cleanly distinguish between incentive and composition effects in our analysis, I later present some results by calendar and risk year that speak to this issue.

Finally, the analysis assumes that there are no productivity spillovers between eligible and ineligible teachers. If, for example, greater effort on the part of probationary teachers induced greater effort on the part of tenured teachers in a school, the DD estimate would tend to understate any positive impact of the policy. While it is possible that such spillovers exist, the contention here is that these effects are likely to be small.

Table 5 shows that the main results described above are robust to a variety of alternative specifications. Rows 2-4 show the results are roughly comparable regardless of whether one measures absences using sick days, personal days or other absences. Row 5 shows that the results fall but are still significant if one excludes observations with more than 40 absences, under the assumption that these are cases of non-discretionary leaves for illness or other reasons. Row 6 shows nearly identical results using only absences between September and March, prior to the time when teachers may have heard they had been non-renewed. Row 7 shows that the results are robust to limiting the control group to include only young (i.e., teachers with 5-10 years of experience) tenured teachers.

Rows 8-9 present results separately using pre-policy assigned and unassigned probationary teachers respectively. In doing so, we limit the analysis to probationary teachers who were in the CPS in 2004 since teachers hired after this year were automatically assigned. When we limit the comparison group to the roughly 23 percent of pre-policy PATs who were not assigned to positions, the dismissal policy does not appear to impact teacher effort. It turns out 
that this is driven by the fact that these unassigned probationary teachers were more productive (i.e., had fewer absences, conditional on all other observables) than the assigned probationary teachers prior to the policy. This is consistent with fact that unassigned teachers had less job security than assigned teachers prior to the policy, and may have been exerting greater effort in the absence of the policy.

Rows 10-13 show that the results are not particularly sensitive to the inclusion of school fixed effects, school-year characteristics or teacher demographics. Finally, in results not reported here but available upon request, I demonstrate that alternative estimates of the standard errors do not have an important effect on the inferences one would draw from the results, including clustering on teacher or experience instead of school as well as a two-way clustering of school and experience or teacher and school.

\subsection{Treatment effect heterogeneity}

Table 6 shows how the effect of the policy varies by school characteristics. The first thing to see is that the impact was roughly 2.5 times larger in elementary schools than in high schools. Moreover, there was significantly more variation in the policy effect across high schools than across elementary schools. In elementary schools, for example, the impacts were roughly equivalent in higher- and lower-performing schools (columns 2-3) and across predominantly Hispanic, predominantly African-American and racially mixed elementary schools (columns 4-6). In high schools, by contrast, the effects were concentrated in lowachieving and predominantly African-American schools. In results not reported here, I find that the policy effects in high schools (but not elementary schools) were concentrated in schools with younger principals (i.e., under the age of 50). 
It is also possible that the policy effect may have varied with the fraction of teachers in the school who were probationary, and thus subject to the new policy. For example, the policy may have been more salient in schools with a large fraction of probationary teachers. To examine this, columns 7-9 show results separately for schools by fraction probationary terciles. For elementary schools, we find no significant differences across subgroup. In high schools, we find the largest effects in the top and bottom terciles, although the differences are not statistically significant.

Table 7 shows results separately for various teacher subgroups. Interestingly, the policy seems to have had a significantly higher impact on younger and female teachers relative to older and male teachers. Given that females had higher rates of absenteeism prior to the introduction of the policy, it may be the case that the policy reduced absences among those at highest risk of absenteeism. To explore this more formally, I predict absence rates based on observable teacher, principal and school characteristics using the pre-reform data, and then estimate the policy effects separately for the top, middle and bottom third of the predicted teacher absence distribution. As expected, the policy had a significantly larger impact on teachers with moderate- and high-predicted absences relative to those with low predicted absences. In high schools, it appears that the impacts were concentrated primarily among Black teachers. In results not reported here, I confirm that this is not simply because Black teachers disproportionately work in low-achieving high schools that experienced the largest policy effects.

Table 8 examines whether the policy effect varies with the likelihood of dismissal. Given that only 10-12 percent of probationary teachers were dismissed under this policy and that 30-40 percent of schools did not dismiss any teachers, many teachers may have perceived little risk of dismissal. For these teachers, one would not expect the policy to have had any substantial 
impact. To explore this potential heterogeneity, I calculate the predicted probability of dismissal for each teacher using a rich set of observable teacher, school and principal characteristics. ${ }^{31}$

Because actual dismissal is potentially endogenous with respect to teacher behavior, it is important that the characteristics one uses in the prediction equation include only pre-determined characteristics and not, for example, teacher absences in the year of dismissal.

Columns 1-4 present the policy effects separately by quartile of this predicted probability. ${ }^{32}$ Elementary teachers in the top quartile (i.e., those most likely to be dismissed) appear to have responded somewhat more than other elementary teachers, although the point estimates are not statistically different across quartiles. The estimates for high school teachers are even less precise, with no significant differences. ${ }^{33}$

\footnotetext{
${ }^{31}$ To do so, I estimate a Conditional Logit model including all probationary teachers in 2005-2007 where the outcome is a binary indicator for whether the teacher was dismissed. In addition to a full set of school $\mathrm{x}$ year effects, predictors all include a rich set of teacher, school and principal characteristics (including all of those shown in Table 3). While the school and principal characteristics are not identified in light of the inclusion of school $\mathrm{x}$ year fixed effects, I include a number of interactions between teacher characteristics and school/principal characteristics that are identified and were found to be predictive of dismissal in previous work (Jacob 2007). I use the coefficients from this model to calculate a predicted probability of dismissal for all teachers in both pre- and post-policy years. The fixed effects are not included in the prediction since these would capture the unobserved, ex-post propensities to dismiss teachers at the school, which may be endogenous to teacher behavior as discussed above. These predictions capture the within-school probability of dismissal, which is consistent with the school fixed effect approach used in identifying the policy effect. Finally, it is worth noting that ideally one would use pre-policy data to calculate dismissal probabilities. Unfortunately, virtually no teachers were dismissed prior to this policy (as least as shown in the formal administrative data), which makes this approach infeasible.

${ }^{32}$ When one examines policy effects by predicted probability of dismissal, one must assume that the predicted probability of dismissal corresponds with a teacher's perception of the likely risk of dismissal.

${ }^{33}$ In results not reported here, I examine whether the policy effects differed by the aggregate school dismissal rates. While ex-post dismissal is clearly endogenous to teacher behavior (as discussed above), school-level splits by broad categories could be interesting if, for example, schools in which no teachers were dismissed were not sufficiently aware of the policy or had other circumstances that might have obviated the need for the policy. For elementary schools, I found only modest size and statistically insignificant differences across groups. In high schools, by contrast, the policy effects seem to be concentrated in schools the $15 \%$ of schools that did not dismiss any teachers. The results here are consistent with a scenario in which teachers respond to the incentives provided by the policy, adjust their behavior accordingly, and thereby avoid dismissal. This dynamic would introduce a negative correlation between changes in teacher effort and ex-post dismissal rates.
} 
Table 9 presents specifications that allow the policy effect to differ by calendar and risk year, as both the incentive and composition components of the policy might vary along these dimensions. Incentive effects may vary with calendar year as teachers and principals become more familiar with the policy. The compositional effects of the policy will obviously differ by calendar year. Probationary teachers in 2004-05, for example, will not have been hired under the new regime, and could not have been dismissed yet, so there should be no compositional effect.

Risk year is defined as the number of years a probationary/temporary teacher has worked in a particular school under the new regime. Prior to the policy, all teachers have a value of zero. In 2005, all PATs and TATs are coded as risk year equals one. In 2006, newly hired teachers will have a value of 1 and teachers who "survived" dismissal in 2005 and remained at the same school are coded as having risk year equal to two. PATs/TATs who switched schools within the district between 2005 and 2006 are coded as risk year one again in 2006 because of prior literature suggesting that firm-specific tenure (as opposed to simply experience) is critical aspect of job security.

A variety of models of employer learning imply that the incentives might diminish with time spent at a particular school under the new regime (e.g., Jovanovic 1978). Intuitively, having "survived" one or more years without being dismissed, a teacher may feel reassured that the principal thinks highly of her. However, risk year will also incorporate compositional effects since, by definition, teachers with higher values will have "survived" dismissal in the past, and might therefore be positively selected.

Because risk year and calendar year are highly correlated, I estimate a parsimonious specification that simply adds two interaction terms to the baseline specification. The key independent variable in the baseline specification is Post Policy x Untenured Teacher. Here I 
include a variable allowing the policy to have a separate effect on teachers in their second or third year under the policy (i.e., Post Policy x Untenured Teacher x Risk year 2 or 3) and allowing the policy to have a separate effect in the second and third years of the policy (i.e., Post Policy x Untenured Teacher x School year 2006 or 2007).

To begin, consider column 1 in panel A. The estimate of -0.713 reflects the impact of the policy in calendar year 2005 (which incorporates, by construction, only teachers with risk year 1). The estimate in the second row of 0.24 indicates that the policy effect was somewhat smaller for teachers who had survived their first year of the policy (i.e., these teachers reduced absences by $.71-.24=.47$ per year as a result of the policy). The estimates in the third row indicate that the effect of the policy was substantially larger in the later years of the policy. Untenured teachers in 2006 and 2007 realized a reduction in absences of roughly 1.2 per year $(.713+.489)$ - an effect 70 percent larger than teachers in 2005. It is important to recognize, however, that the differential effects for 2006 and 2007 reflect not only any change in incentives, but also compositional changes due to dismissals and new hiring. The remaining columns show results from the same specification estimated on different subsamples of schools.

\subsection{Impacts on Student Achievement}

As noted earlier, the CPS data does not have the information necessary to link individual teachers to students over the analysis period, which precludes examining the impact of the policy on student achievement using the strategy described above. Instead, I estimate a difference-indifference model at the school-year level, comparing within-school changes in student achievement over time between schools with higher versus lower fractions of probationary teachers at the time the policy was implemented. The intuition behind this approach is that 
schools with a higher fraction of probationary teachers in 2005 experienced a larger "dose" of the treatment. For example, if the policy induces effort among teachers at risk of dismissal, then these schools should experience greater increases in effort, ceteris paribus. Similarly, these schools have the potential to undergo greater turnover, thus realizing greater compositional changes.

To illustrate the intuition behind this strategy, Figures 7 and 8 plot the standardized math and reading scores 2003 through 2007 separately for elementary schools with the highest and lowest fractions of probationary teachers in 2005. Looking first at all elementary schools in panel A, we see little evidence of differential achievement trends across the schools. When we focus on low-achieving schools in Panel B, however, there is some evidence that schools with a high fraction of probationary teachers experienced more rapid growth in student achievement following the introduction of the dismissal policy, relative to schools with a lower share of probationary teachers.

The trends in Figures 7 and 8 do not control for any student or teacher characteristics.

One obvious concern with this strategy is that the fraction of probationary teachers in a school in 2005 is likely correlated with other factors (both observable and unobservable) that might influence subsequent achievement. To account for this, I estimate the following model:

$$
\begin{aligned}
Y_{s t}= & \beta_{0}+\beta_{1}\left(\% P A T 05_{s t}\right)+\beta_{2}\left(\text { post }_{t}\right)+\beta_{3}\left(\text { post }_{t} * \% P A T 05_{s t}\right)+ \\
& \beta_{4}\left(\% \text { lowinc } 05_{s t}\right)+\beta_{5}\left(\text { post }_{t} * \% \text { olowinc } 05_{s t}\right)+Z_{s t}+\gamma_{t}+\lambda_{s}+\varepsilon_{s t}
\end{aligned}
$$

where $Y_{s t}$ is a measure of student achievement in school $s$ in year $t .^{34}$ The model includes (a) school fixed effects $\lambda_{s}$ (which control for any such time-invariant school characteristics that

\footnotetext{
${ }^{34}$ The achievement measures used in this analysis come from the Illinois Standards Achievement Test (ISAT), which was the primary standardized exam given to students in Illinois. Because in the earlier years of the period the exam was only administered to students in grades 3,5 and 8, we limit the analysis to these grades. Specifically, we take the school-grade-year average scale scores, standardize these to have mean zero and standard deviation one,
} 
might be associated with initial teacher experience levels and subsequent student achievement such as a particularly dangerous neighborhood or aging school facilities), (b) time-varying student characteristics $Z_{s t}$ and (c) time-varying measures of teacher experience, also included in $Z_{s t}{ }^{35}$ The teacher experience measures are important because of the well-established experienceeffectiveness gradient in teaching, coupled with the fact that schools with more probationary teachers in 2005 will, by definition, have more teachers progressing through their early teaching years over the period. In addition, I control for an interaction between the fraction low-income in 2005 and a post-policy indicator to account for the fact that schools with a disproportionate number of probationary teachers also have a more disadvantaged student population, and achievement may have changed in low-income schools for reasons unrelated to the dismissal policy. The coefficient on the interaction between post and \%PAT05, $\beta_{3}$, measures the achievement effect of the policy. ${ }^{36}$

Table 10 shows estimates corresponding to equation (2). Columns 1-3 present the coefficients on the interaction between a post-policy indicator and the fraction of teachers in the school in 2004-05 that was probationary. The regressions are weighted by student enrollment, and standard errors are clustered by school. The top panel shows results using the school average scale score in math as the outcome, standardized using the standard deviation in school

and then create an average standardized measure for each school-year weighting by the number of students tested in a particular school-grade-year. For the proficiency outcomes, we simply use the weighted average of the fraction proficient (or higher) in the school-year, again weighting by the number of tested students in each school-gradeyear.

${ }^{35}$ Time-varying covariates include fraction Black, fraction Hispanic, fraction eligible for free lunch, teacher experience and its square and the fraction of teachers with less than 3 years of experience.

${ }^{36}$ In order for this strategy to provide reliable results, there must be substantial variation in the school fraction of probationary teachers across schools that have similar poverty and/or achievement levels. Fortunately, this appears to be the case. For elementary schools, the mean within school percent probationary (untenured) teachers in 2005 was $33 \%(43 \%)$, the 90 th percentile was $50 \%(65 \%)$ and the 10 th percentile was $19 \%(26 \%)$. Importantly, the fraction untenured in a school in 2005 was only modestly correlated with student demographics (correlation of .2 with fraction eligible for free-lunch) and student achievement (correlation of -.29 with fraction meeting proficiency standard). This suggests that there will be substantial variation in probationary status that is not correlated with other observable school characteristics to allow independent identification of $\beta_{3}$ and $\beta_{5}$ above. 
mean scores (as opposed to the student-level standard deviation). The point estimate of .127 (column 1) is not statistically significant. However, it is worth noting that the implied effect is quite large. Given that the student standard deviations are roughly double the standard deviation in school means, if we assume zero spillovers from probationary to tenured teachers, these results suggest an effect size of roughly .25 student standard deviations among "treated" (i.e., probationary) teachers. Equivalently, the point estimates suggest that a 30 -percentage point increase in the fraction of probationary teachers at the school would be associated with an increase in student achievement of $.3 \times .25 \sim .08$ standard deviations.

Looking at low- and high-achieving elementary schools in columns 2 and 3 respectively, we see that the point estimates for low-achieving schools are roughly double those in highachieving schools. None of the estimates, however, is statistically different than zero. The pattern of results for fraction of students scoring at or above the proficient level, shown in the second panel, is roughly comparable as are the findings for reading, shown in panels 3 and 4 .

As discussed earlier, it appears that the policy increased effort among temporary teachers as well as probationary teachers, in which case one might want to use the fraction of teachers in a school who were untenured (i.e., probationary or temporary) as the measure of treatment. The specifications shown in columns 4-6 do exactly this, estimating equation (2) where fraction untenured is substituted for fraction probationary. The results are qualitatively similar to those in columns 1-3, but somewhat larger and a bit more precisely estimated such that some of the estimates for low-achieving schools are significantly different than zero at conventional levels. ${ }^{37}$

Overall, these results provide only tentative evidence that the policy increased student achievement scores in elementary schools. However, as noted earlier, the point estimates

\footnotetext{
${ }^{37}$ None of the estimates presented here is sensitive to the student enrollment weighting or to the use of the natural logarithm of achievement (or the log odds of fraction proficient) as the outcome.
} 
suggest potentially large effects. Moreover, based on prior estimates of the relationship between teacher absences and student achievement, it appears that the observed decline in teacher absences can only explain a tiny fraction of the teacher effort response. ${ }^{38}$ In high schools, by contrast, I find no evidence that the policy influenced student achievement, consistent with the much smaller effects on teacher absences in this level (results available upon request).

\section{Conclusions}

In this paper, I take advantage of a unique policy change in the Chicago Public Schools (CPS) to estimate the effect of employment protection on worker effort. My results suggest that the reduction of job security for probationary teachers in Chicago led to a 10-20 percent reduction in teacher absenteeism. The effects were strongest among teachers in elementary schools and in low-achieving, predominantly African-American high schools, and among teachers with high-predicted absences.

This study makes several important contributions. First, it informs the economic literatures on employment protection policies and teacher incentives. To the best of my knowledge, it is one of the few empirical studies of the impact of employment protection on worker effort, and the only study to directly examine this issue in the public sector (let alone in education). Second, the findings presented here have important implications for current

\footnotetext{
${ }^{38}$ If one estimates equation (2) using teacher absences at the outcome, one finds that a 30-percentage point increase in fraction untenured is associated with $0.7 \times 0.3=0.21$ fewer absences. Prior research suggests that a reduction of 1 teacher absence increases student achievement by about 0.002 student standard deviations (Clotfelter et al. 2007, Miller et al. 2007). Hence if achievement were operating solely through reduced teacher absence, then one would expect a 30-percentage point increase in the fraction untenured to result in a $0.21 \times 0.002=0.00042$ student standard deviation gain in achievement. The estimates in Table 10 are measured in terms of school-level standard deviations, which are roughly half the size of the student-level standard deviation in Chicago elementary schools during this period. For example, in 2006, the student s.d. of reading scores in grades 3, 5 and 8 was roughly 29,28 and 23 compared with the school s.d. of 13,13 and 10. In math, the corresponding figures are 29, 27 and 26 compared with 15, 14 and 13 . Hence, the point estimate of 0.195 school-level s.d. in column 4 of the top panel corresponds to an effect of $0.195 \times 2=0.39$. A $30 \mathrm{pp}$ effect would be $0.3 \times 0.39=0.117$. Hence, teacher absences can only explain roughly $0.00042 / 0.117=0.004$, less than 1 percent, of the effect of the policy.
} 
education policy debates. Specifically, the decline in teacher absenteeism following the introduction of the policy provides the most compelling evidence to date that changes in teacher contract provisions can improve student.

At the same time, the apparent reluctance of many principals to utilize the additional flexibility granted under the new contract in Chicago speaks to the potential importance of teacher supply and/or social norms governing employment relations in schools. This suggests that contractual changes alone will not be sufficient to change the practice of promotion and tenure in teaching. 


\section{References}

Autor, David H., John Donohue III, and Stewart J. Schwab, "The Employment Consequences of Wrongful-Discharge Laws: Large, Small, or None at All?" American Economic Review Papers and Proceedings 93:2 (2004), 440-446.

Autor, David, William Kerr and Adriana Kugler (2007). "Do Employment Protections Reduce Productivity? Evidence from U.S. States”, 2007, The Economic Journal, 117 (June), F189-F217.

Autor, David H., John J. Donohue III and Stewart J. Schwab (2006). "The Costs of WrongfulDischarge Laws.” Review of Economics and Statistics 88(2): 211-231.

Ballou, D. (2000). Teacher Contracts in Massachusetts. Boston, MA: Pioneer Institute for Public Policy.

Bertola, Giuseppe. 1990. Job security, employment, and wages. European Economic Review 34, no. 4:851-79.

Besley, Timothy, and Robin Burgess. 2004. Can labor regulation hinder economic performance? Evidence from India. Quarterly Journal of Economics 119, no. 1:91-134.

Bird, R. and Knopf, J. (2009). _'Do wrongful discharge laws impair firm performance?" The Journal of Law and Economics, 52(May): XXX.

Bradley, Steve, Colin Green, and Gareth Leeves. 2007. "Worker Absence and Shirking: Evidence from Matched Teacher-School Data." Labour Economics, 14(3), 319-34.

Bauer, Thomas, Stefan Bender and Holger Bonin. 2007. Dismissal Protection and Worker Flows in Small Establishments. Economica 74: 804-821.

Clotfelter, C. T., Ladd, H. F., \& Vigdor, J. L. (2007). Are Teacher Absences Worth Worrying About in the U.S.?" NBER Working Paper \#13648.

Duflo, E., \& Hanna, R. (2006). Monitoring Works: Getting Teachers to Come to School: C.E.P.R. Discussion Papers CEPR Discussion Papers: 5426.

Educational Research Service. 1980. "Employee Absenteeism: A Summary of Research," Arlington, VA: Educational Research Service.

Ehrenberg, Ronald G., Randy A. Ehrenberg, Daniel I. Rees, and Eric L. Ehrenberg. 1991. "School District Leave Policies, Teacher Absenteeism, and Student Achievement." Journal of Human Resources, 26(1), 72-105.

Fama, Eugene. 1980. "Agency Problems and the Theory of the Firm." The Journal of Political Economy, 88(2), 288-307. 
Figlio, D. and with Lawrence Getzler. 2006. Accountability, ability and disability: Gaming the system? In Advances in Microeconomics, Vol. 14: Improving School Accountability - Checkups or Choice?, ed. T. Gronberg and D. Jansen, 35-49. Amsterdam: Elsevier.

Figlio, D., with J. Winicki. 2005. Food for thought? The effects of school accountability plans on school nutrition. Journal of Public Economics 89(2-3): 381-94.

Friesen, Jane. 2005. "Statutory firing costs and lay-offs in Canada", Labour Economics, 12(2): 147-168.

Hansen, Michael. 2009a. Career concerns incentives and teacher effort. University of Washington Working Paper.

Hanushek, Eric A. (1994). Making Schools Work: Improving Performance and Controlling Costs. Brookings Institution Press, Washington, DC.

Hanushek, Eric A., John F. Kain, Daniel M. O’Brien and Steven G. Rivkin, “The Market for Teacher Quality," NBER Working Paper No. 11252 (2005).

Eric A. Hanushek, “Assessing the Effects of School Resources on Student Performance: An Update," Educational Evaluation and Policy Analysis 19(1997): 141-164.

Hanushek, Eric A. and Margaret E. Raymond (2005) "Does School Accountability Lead to Improved Student Performance?” Journal of Policy Analysis and Management 24(2): 297-327.

Haynes, V. D. (2008, July 3, 2008). Rhee Seeks Tenure-Pay Swap for Teachers. The Washington Post.

Hess, F. M., \& Loup, C. (2008). The Leadership Limbo: Teacher Labor Agreements in America's Fifty Largest School Districts. Washington, D.C.: Thomas B. Fordham Institute.

Holmström, Bengt. 1982. "Managerial Incentive Problems: A Dynamic Perspective," Essays in Economics and Management in Honor of Lars Wahlbeck. Helsinki: Swedish School of Economics. Reprinted in Review of Economic Studies (1999), 66(1): 169-182.

Hopenhayn, Hugo, and Richard Rogerson. 1993. Job turnover and policy evaluation: A general equilibrium analysis. Journal of Political Economy 101, no. 5:915-38

Hoxby, Caroline M. , Editor, (2003). The Economics of School Choice. University of Chicago Press. Chicago.

Hunt, Jennifer. 2000. "Firing Costs, Employment Fluctuations, and Average Employment: An Examination of Germany", Economica, 67(266):177-202. 
Ichino A., Riphahn R., "The Effect of Employment Protection on Worker Effort. A Comparison of Absenteeism During and After Probation.", Journal of the European Economic Association, March 2005, 3(1): 120-143.

Jackson, Kirabo C. and Elias Bruegmann (2009). "Teaching Students and Teaching Each Other: The Importance of Peer Learning for Teachers." American Economic Journal: Applied Economics, 1(4): 1-27.

Jacob, Brian (2005) “Accountability, Incentives and Behavior: the Impact of High-Stakes Testing in the Chicago Public Schools." Journal of Public Economics 89(5-6): 761-796.

Jacob, Brian A. (2007). “Do Principals Fwere the Worst Teachers?” Working paper.

Jacob, Brian A. and Walsh, Elias (2009). "What's in a Rating? The Relationship between Principal Ratings and Teacher Productivity." Working Paper.

Jacob, Brian, Lars Lefgren and David Sims (Forthcoming). "The Persistence of Teacher Effects." Journal of Human Resources.

Jovanovic, Boyan (1979). "Job Matching and the Theory of Turnover." Journal of Political Economy, 87(5): 972-990.

Kugler, Adriana D. (1999). "The Impact of Firing Costs on Turnover and Unemployment: Evidence from the Colombian Labour Market Reform." International Tax and Public Finance, 6, 389-410.

Kugler, Adriana, Giovanni Pica. 2008. Effects of Employment Protection on Job and Worker Flows: Evidence from the 1990 Italian Reform, Labour Economics 15(1): 78-95.

Lavy, Victor (2007). "Using Performance-Based Pay to Improve the Quality of Teachers", The Future of Children, Spring 2007, 87-110.

Lazear, Edward P. 1990. Job security provisions and employment. Quarterly Journal of Economics 105, no. 3:699-726.

Marinescu, Ioana (2009). "Job Security Legislation and Job Duration: Evidence from the United Kingdom.” Journal of Labor Economics, 27(3): 465.

Martins, Pedro S. (2009). "Dismissals for Cause: The Difference that Just Eight Paragraphs Can Make.” Journal of Labor Economics 27(2): 257-279.

Miller, Reagen T., Murnane, Richard J. and John B. Willet (Forthcoming). "Do Worker Absences Affect Productivity? The Case of Teachers." International Labor Review.

Neal, Derek A. and Diane Schanzenbach (Forthcoming). "Left Behind by Design: Proficiency Counts and Test-Based Accountability." Review of Economics and Statisics. 
Petrin, A. and Sivadasan, J. (2006). "Job security does affect economic efficiency: theory, a new statistic, and evidence from Chile", NBER Working Paper 12757.

Podgursky, M. and Springer, M.G. (2007). "Teacher Performance Pay: A Review.” Journal of Policy Analysis and Management, 26(4).

Prendergast, Canice (1999). "The Provision of Incentives in Firms.” Journal of Economic Literature, 37(1): 7-63.

Price, M. (2009). Teacher Union Contracts and High School Reform. Seattle, WA: Center on Reinventing Public Education.

Rockoff, Jonah E. 2004. "The Impact of Individual Teachers on Students' Achievement: Evidence from Panel Data." American Economic Review, 94(2), 247-52.

Thomas J. Kane, Jonah E. Rockoff and Douglas O. Staiger (2009), "What Does Certification Tell Us About Teacher Effectiveness? Evidence from New York City," Economics of Education Review, 27(6): 615-631. 
Figure 1: Time Trend of Teacher Absences by Status, All Schools

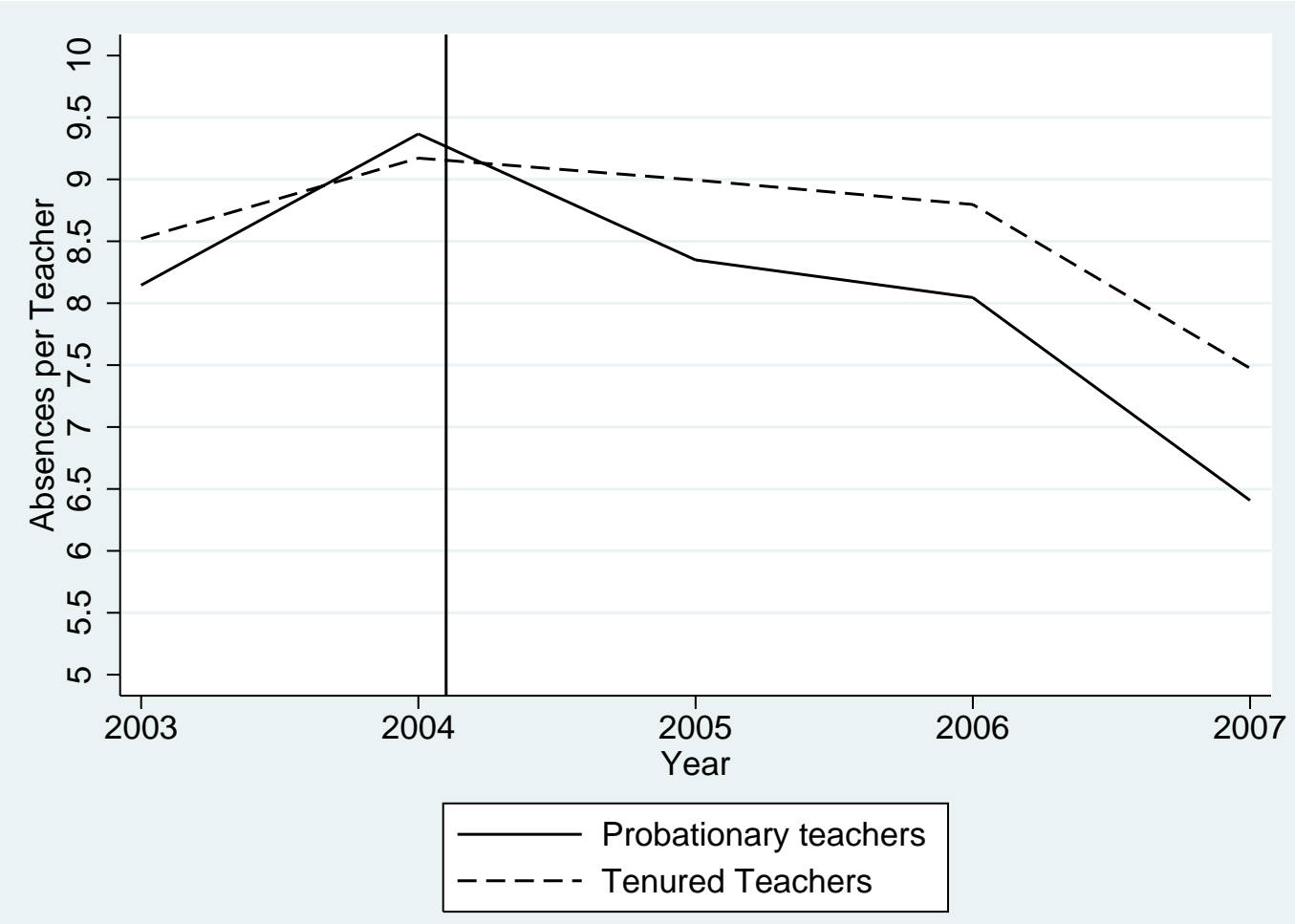

(a) Absences per Teacher

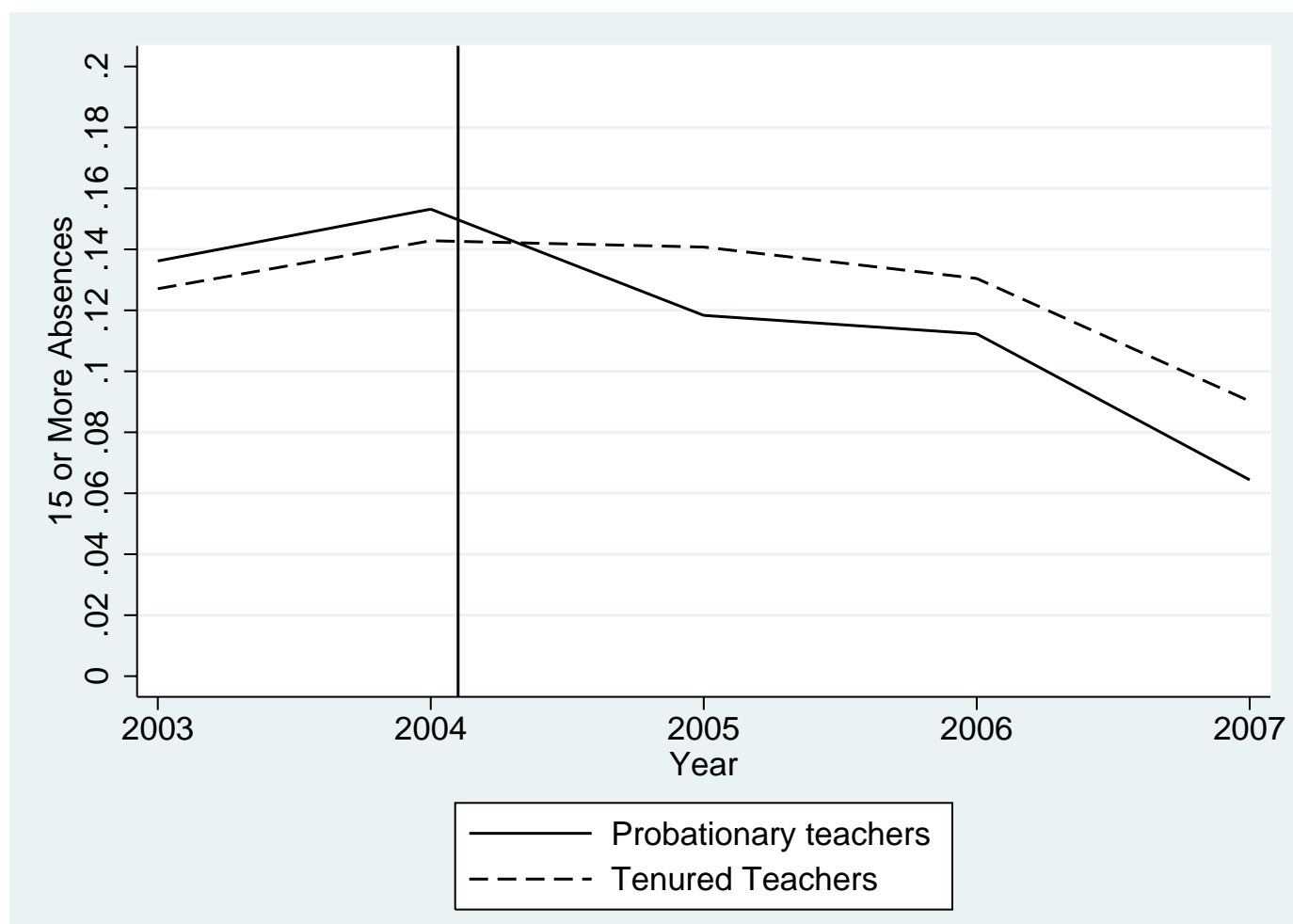

(b) Fraction of Teachers with 15 or More Absences 
Figure 2: Time Trend of Teacher Absences by Status, Elementary Schools

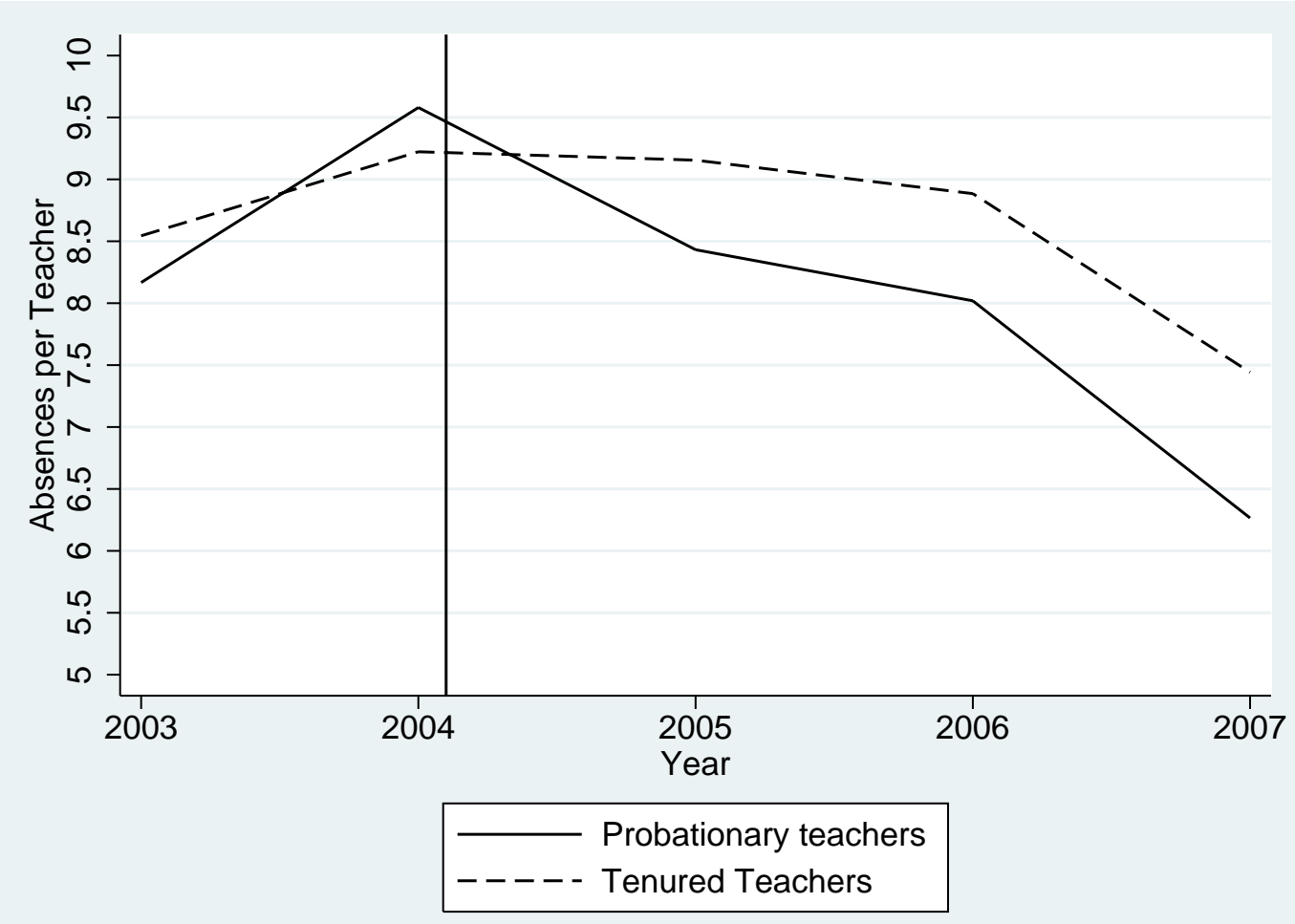

(a) Absences per Teacher

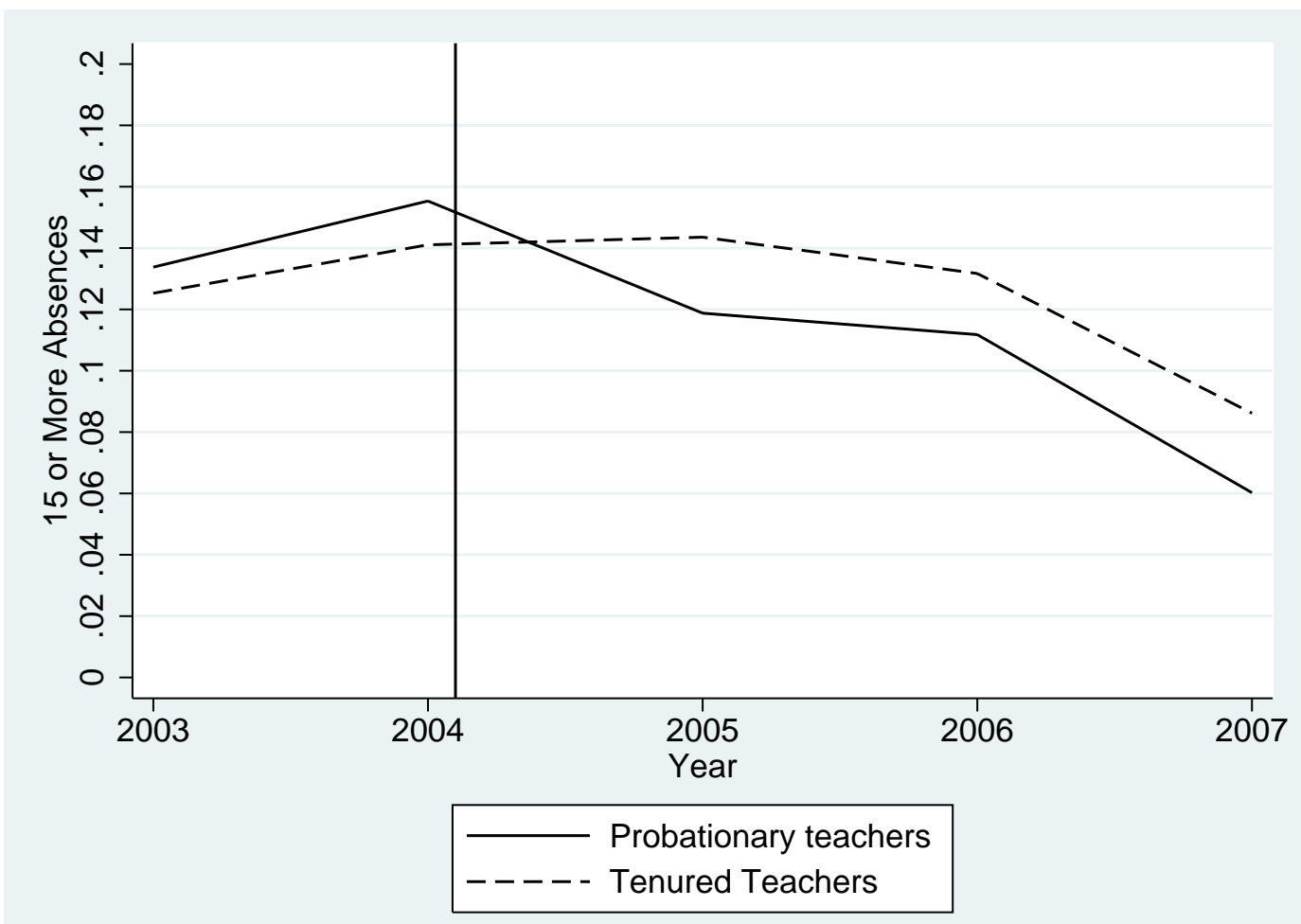

(b) Fraction of Teachers with 15 or More Absences 
Figure 3: Time Trend of Teacher Absences by Status, High Schools

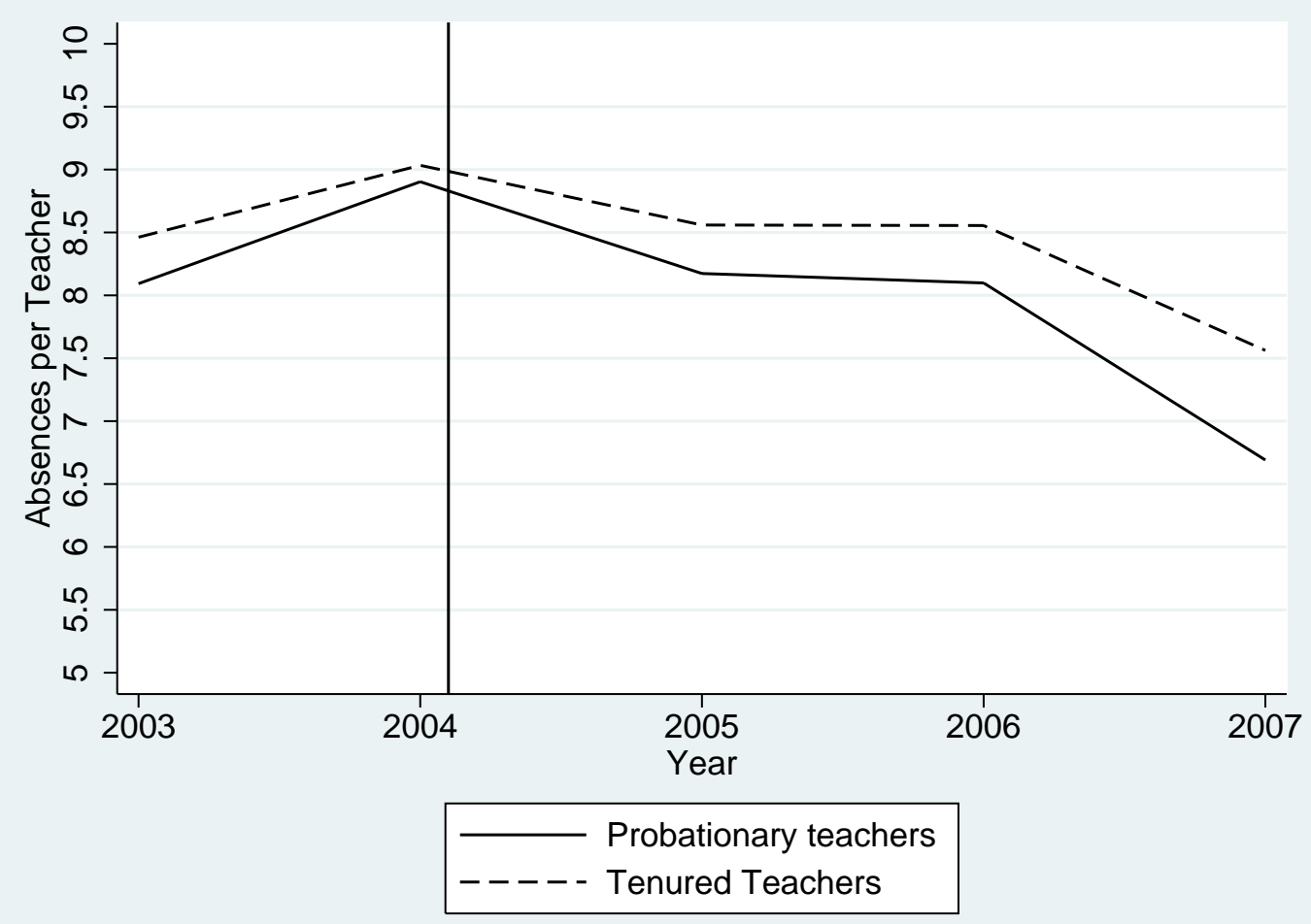

(a) Absences per Teacher

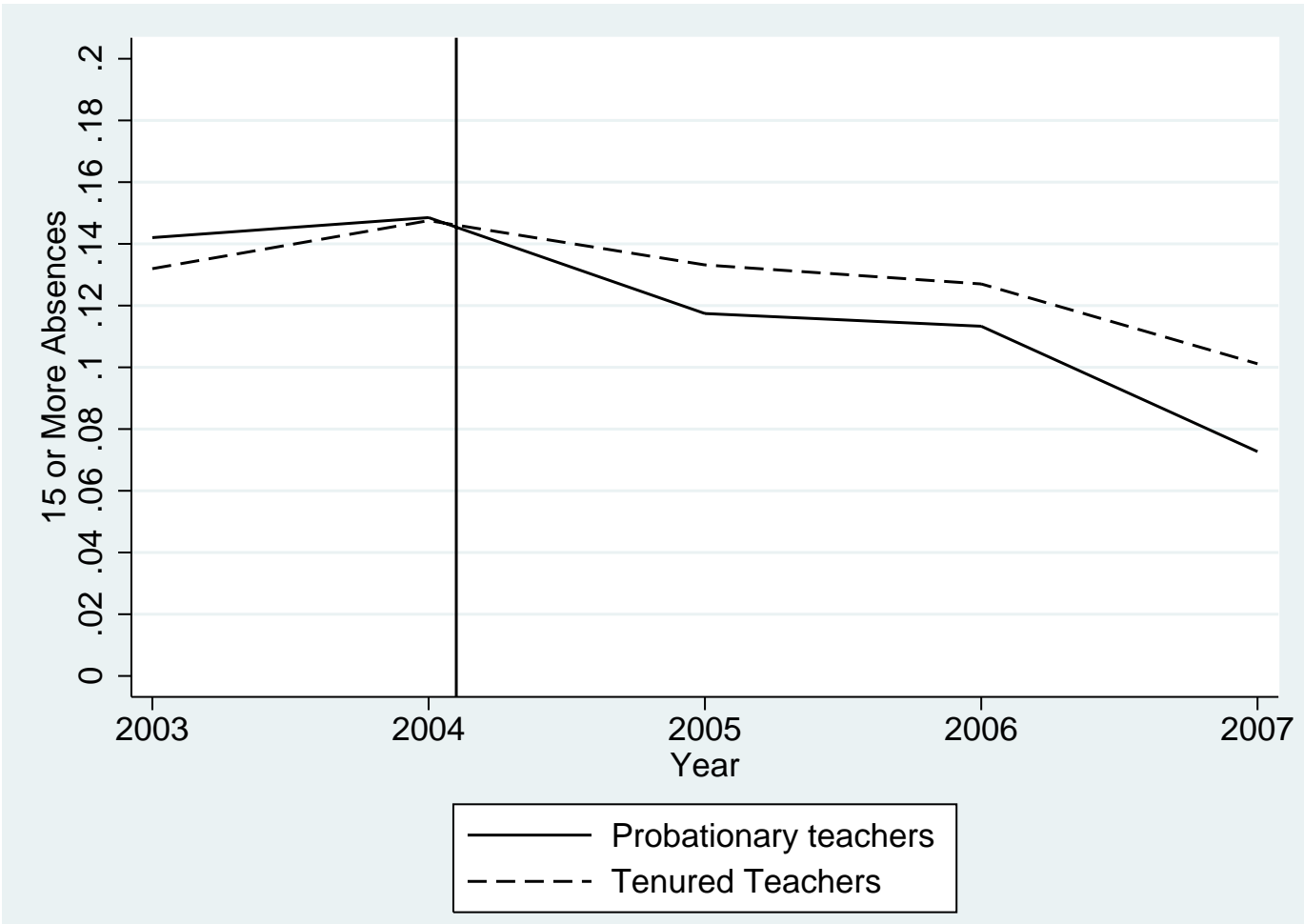

(b) Fraction of Teachers with 15 or More Absences 
Figure 4: Time Trend of Teacher Absences by Experience, All Schools

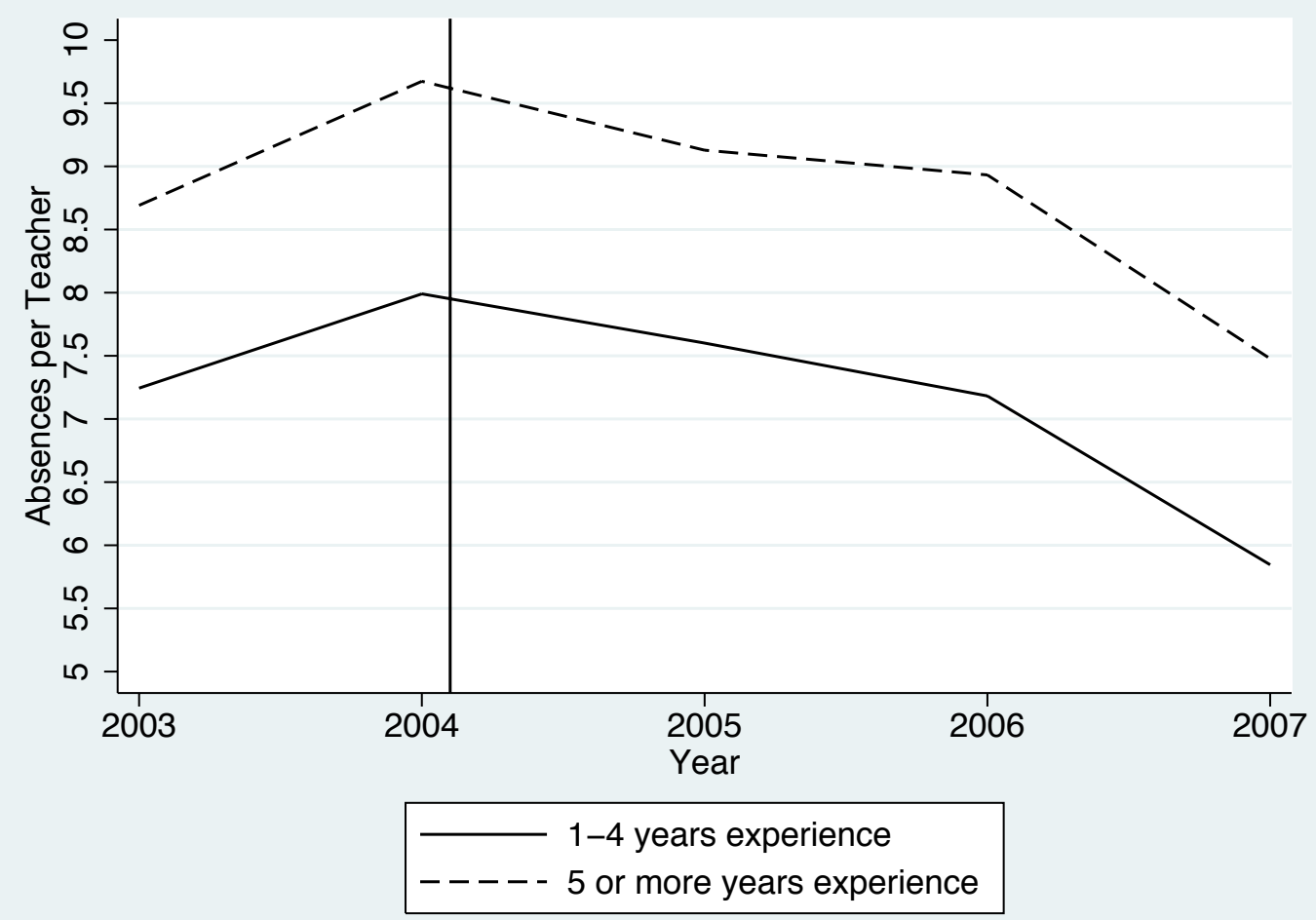

(a) Absences per Teacher

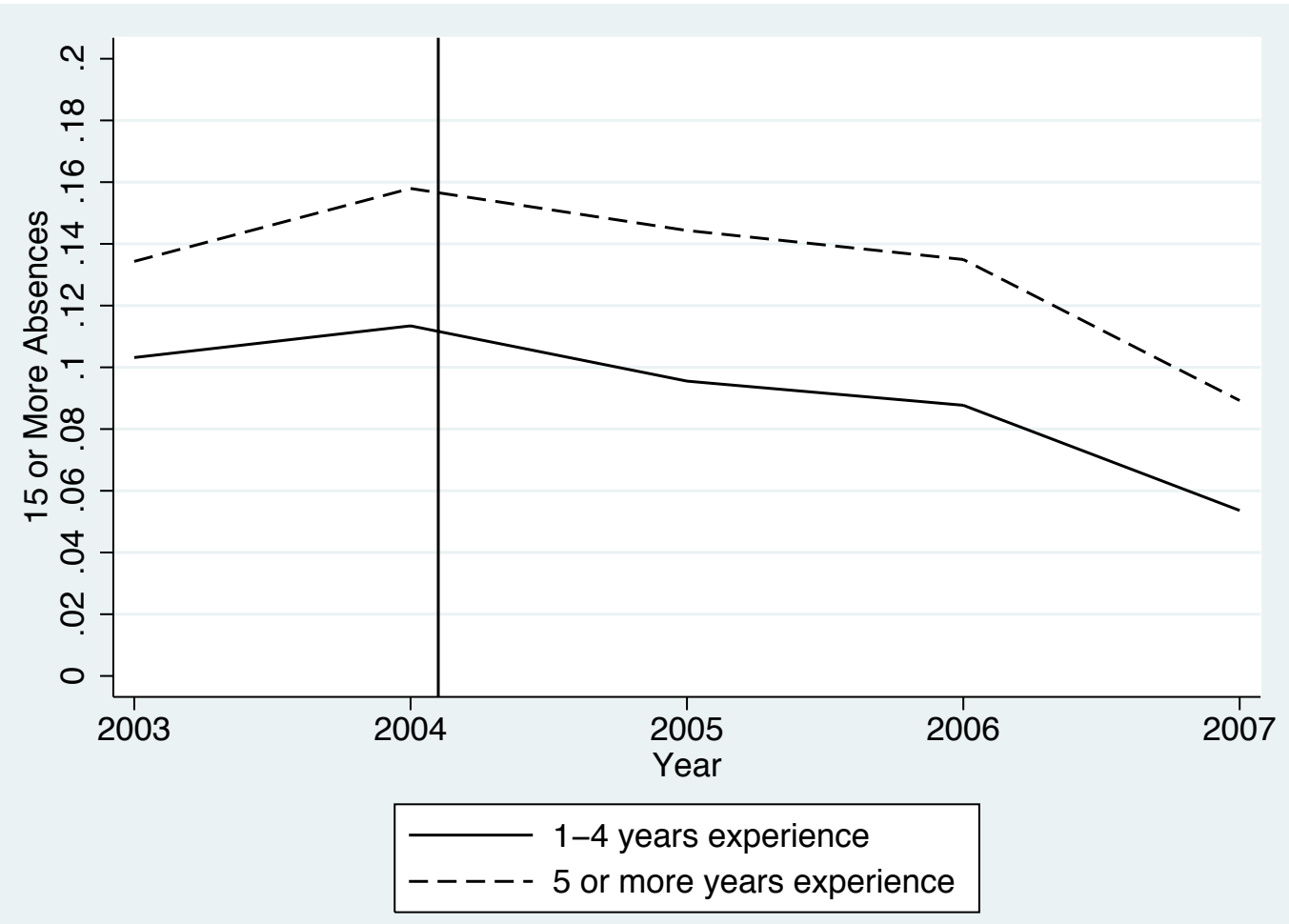

(b) Fraction of Teachers with 15 or More Absences 
Figure 5: Time Trend of Teacher Absences by Experience, Elementary Schools

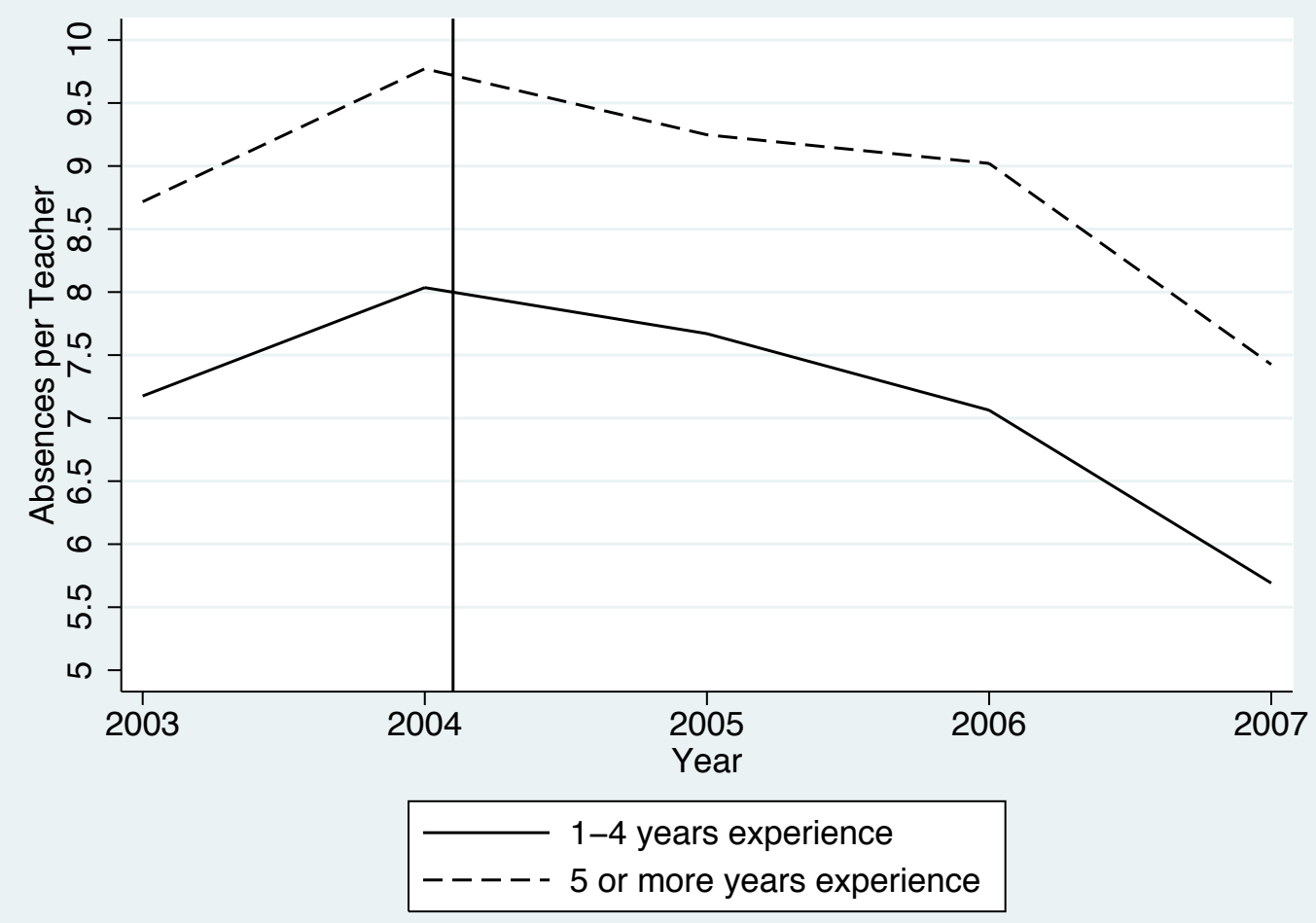

(a) Absences per Teacher

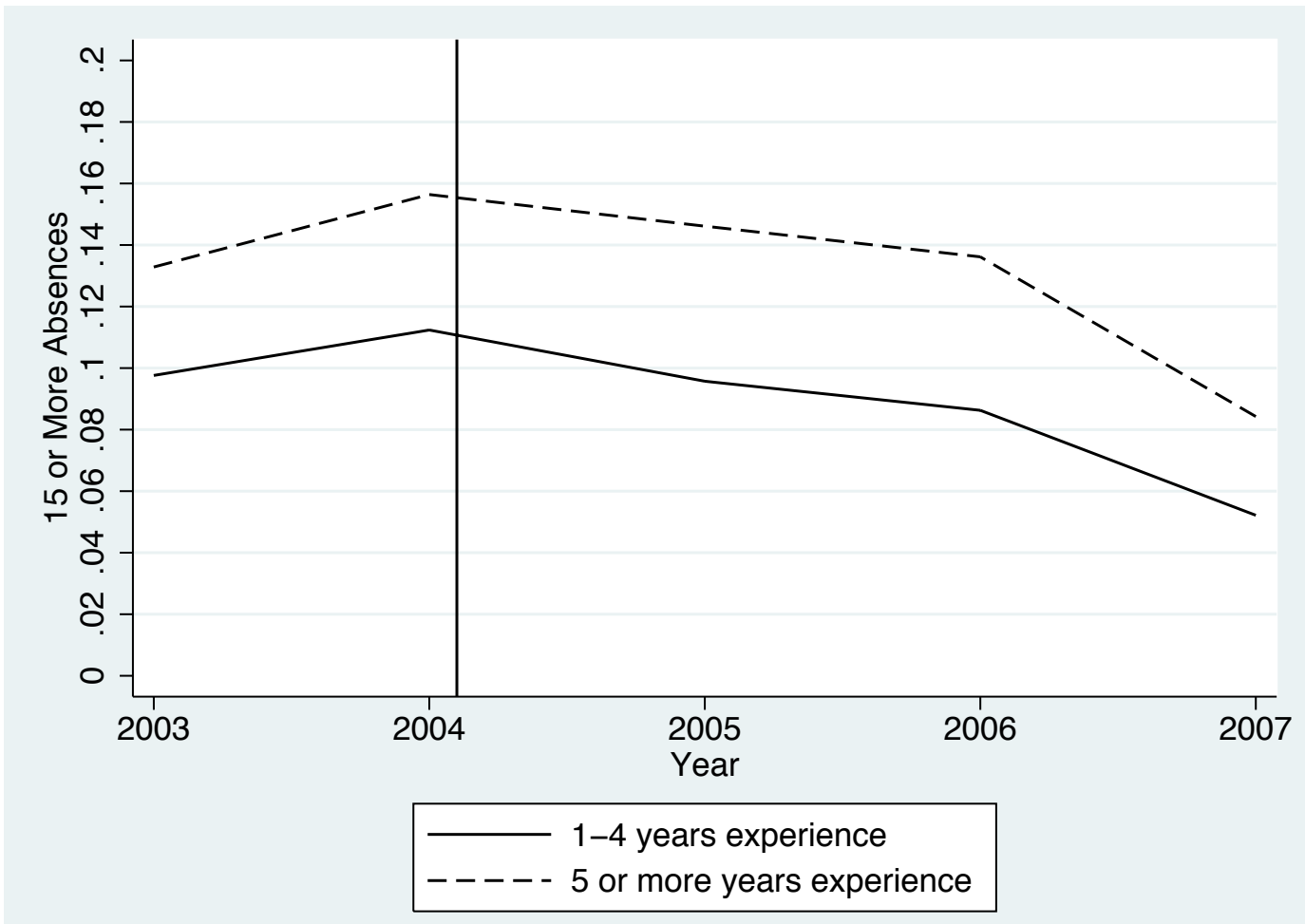

(b) Fraction of Teachers with 15 or More Absences 
Figure 6: Time Trend of Teacher Absences by Experience, High Schools

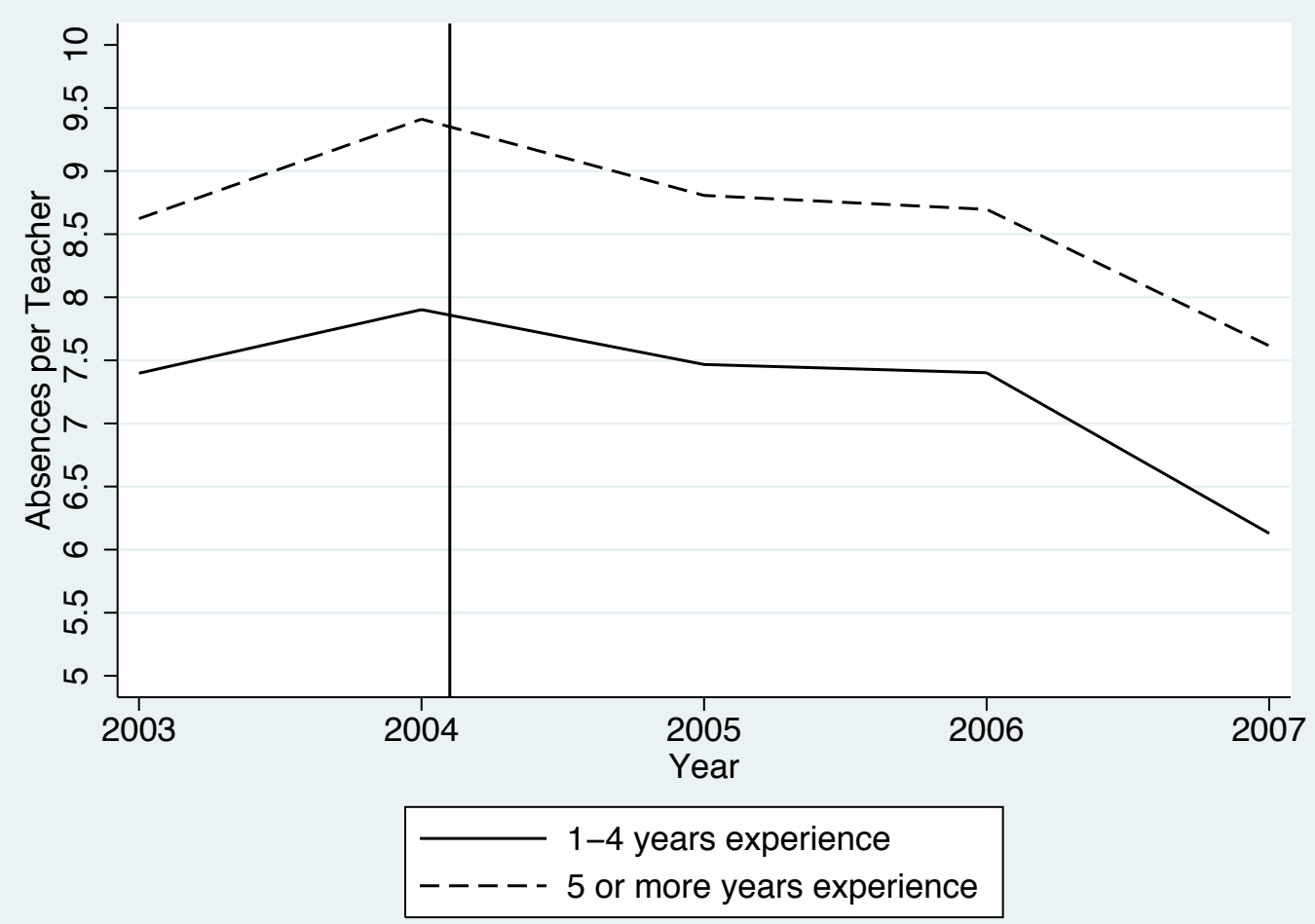

(a) Absences per Teacher

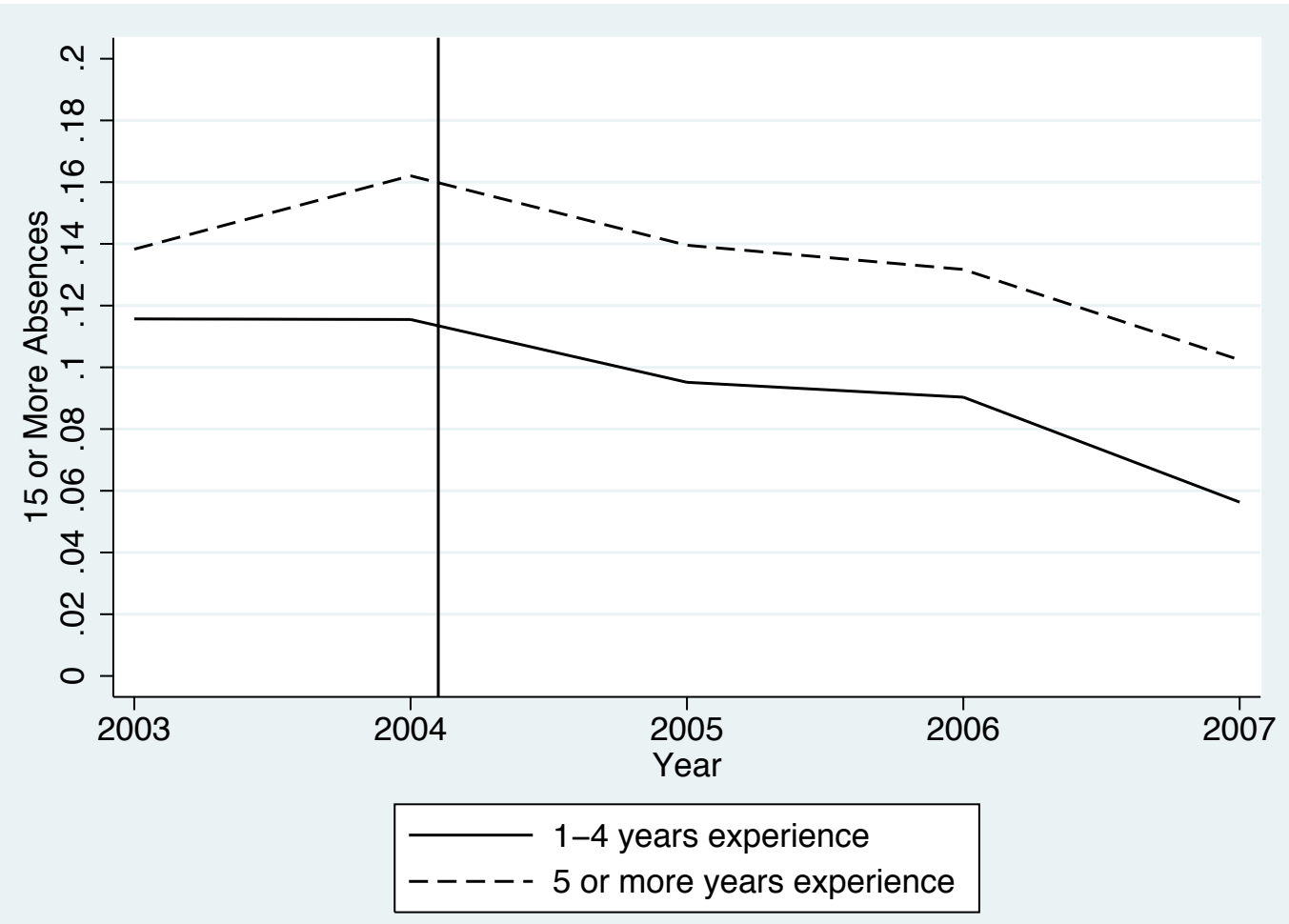

(b) Fraction of Teachers with 15 or More Absences 
Figure 7: Time Trend of School-Level Math Achievement by Fraction Probationary in School in 2005, Elementary Schools

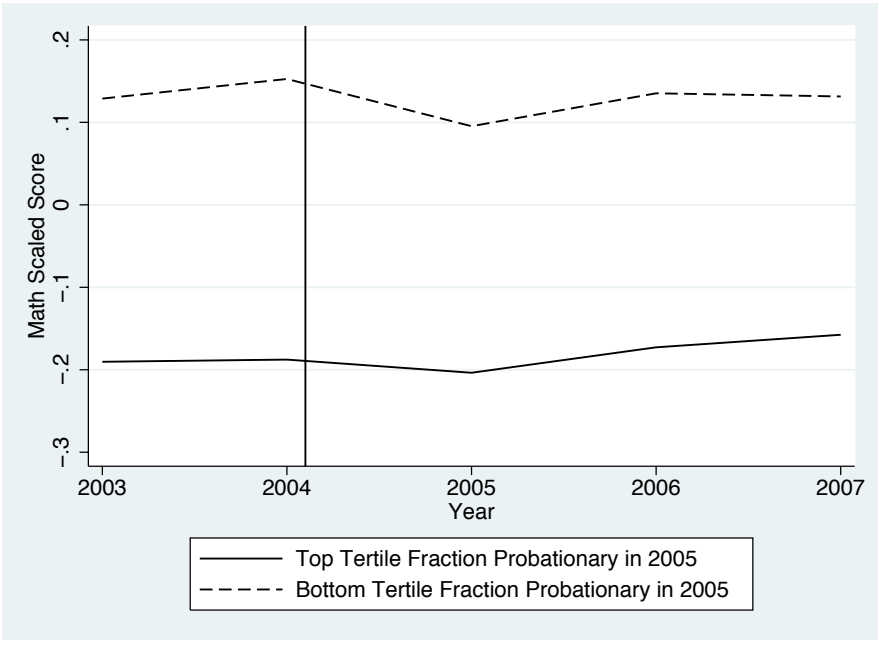

(a) Scaled Scores, All Elementary Schools

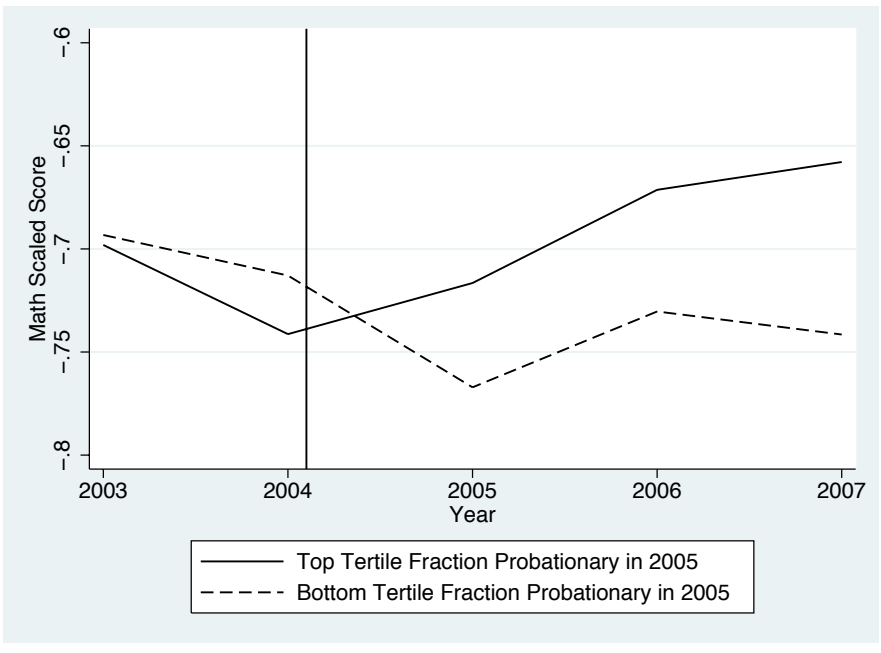

(b) Scaled Scores, Low Achieving Elementary Schools

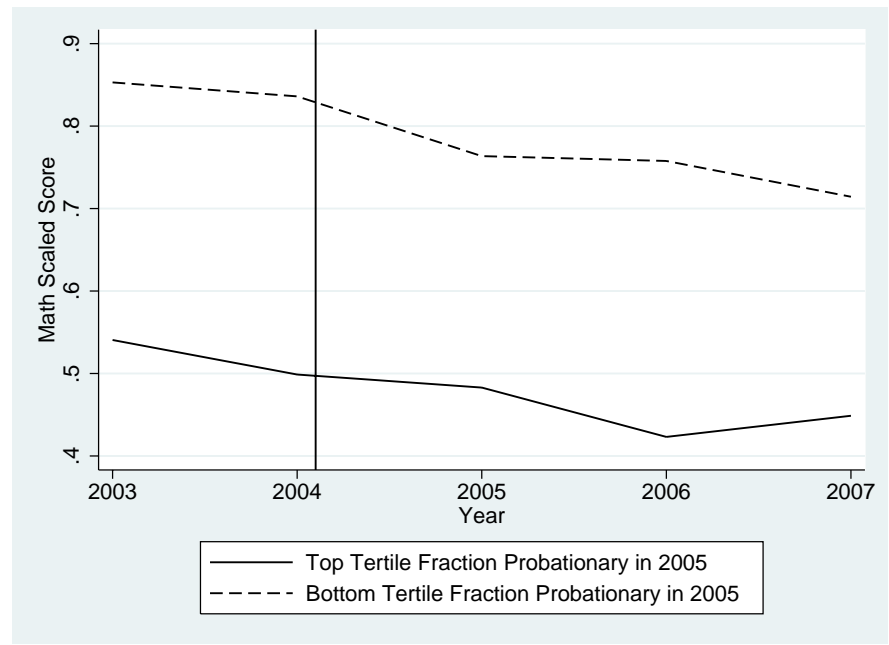

(c) Scaled Scores, High Achieving Elementary Schools 
Figure 8: Time Trend of School-Level Reading Achievement by Fraction Probationary in School in 2005, Elementary Schools

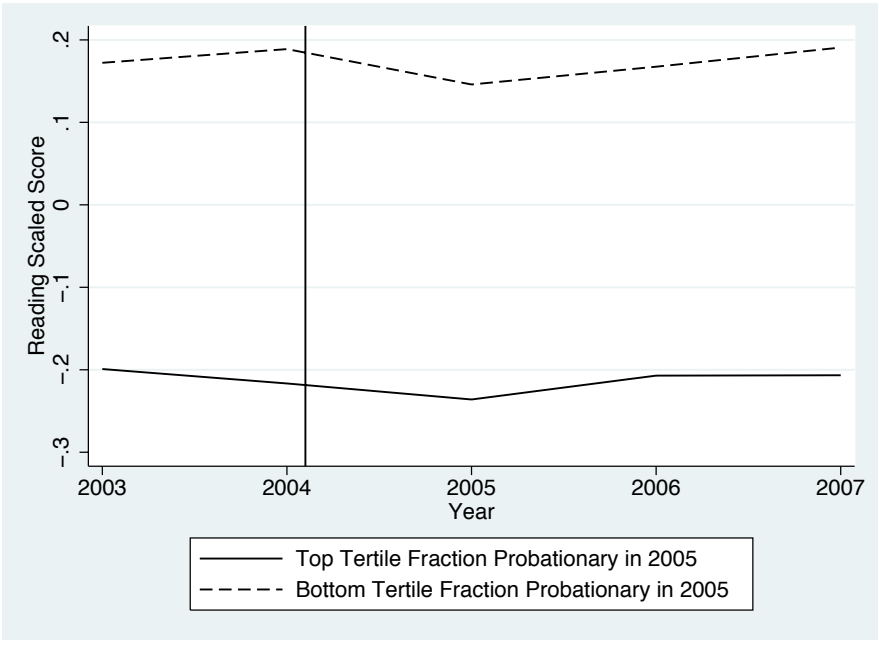

(a) Scaled Scores, All Elementary Schools

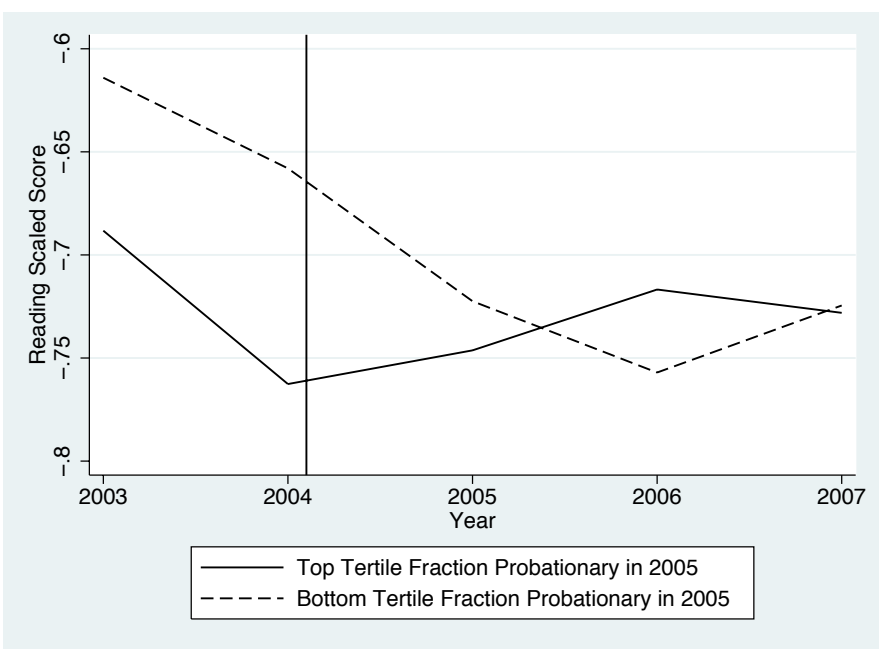

(b) Scaled Scores, Low Achieving Elementary Schools

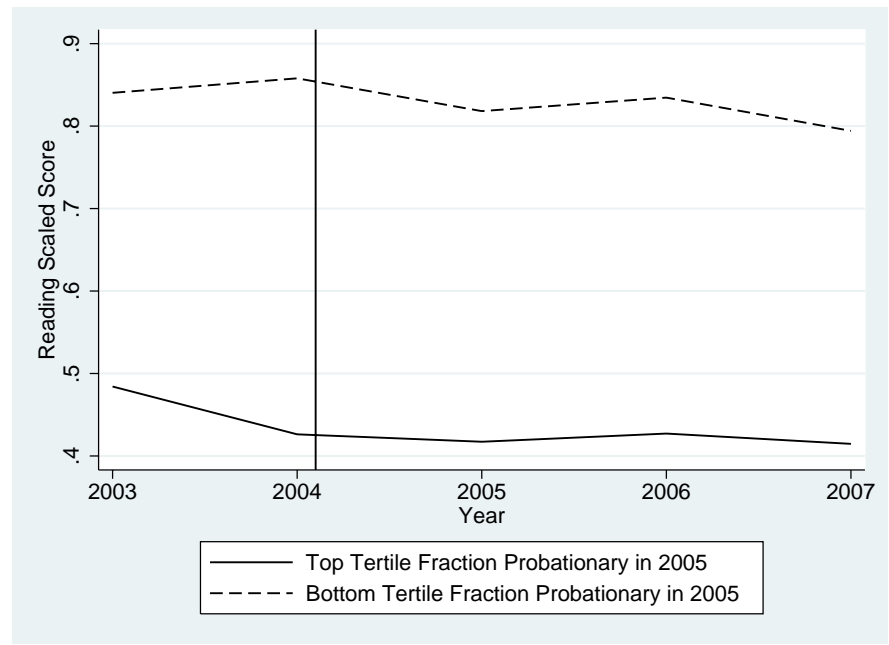

(c) Scaled Scores, High Achieving Elementary Schools 


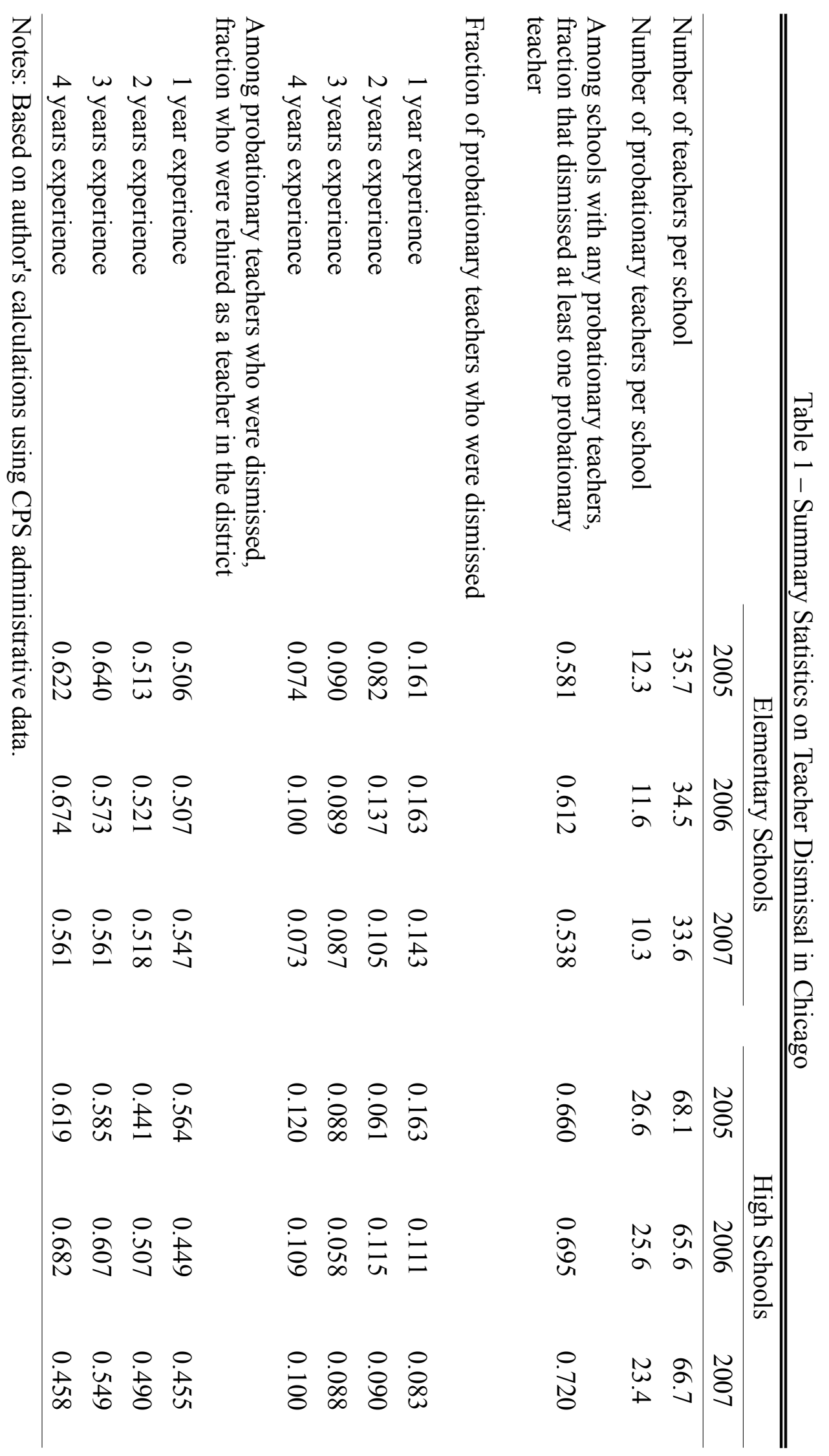




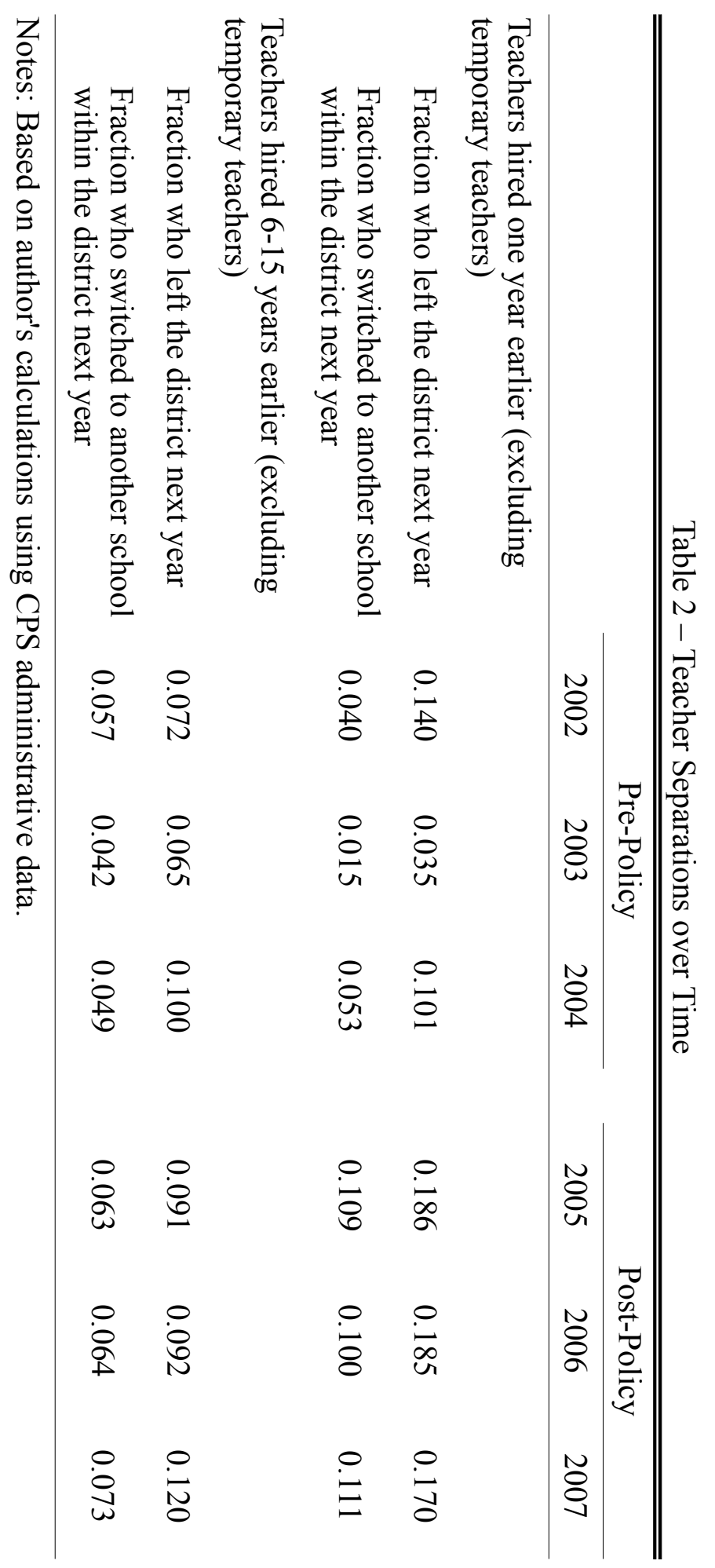


Table 3 - Summary Statistics for Analysis Sample

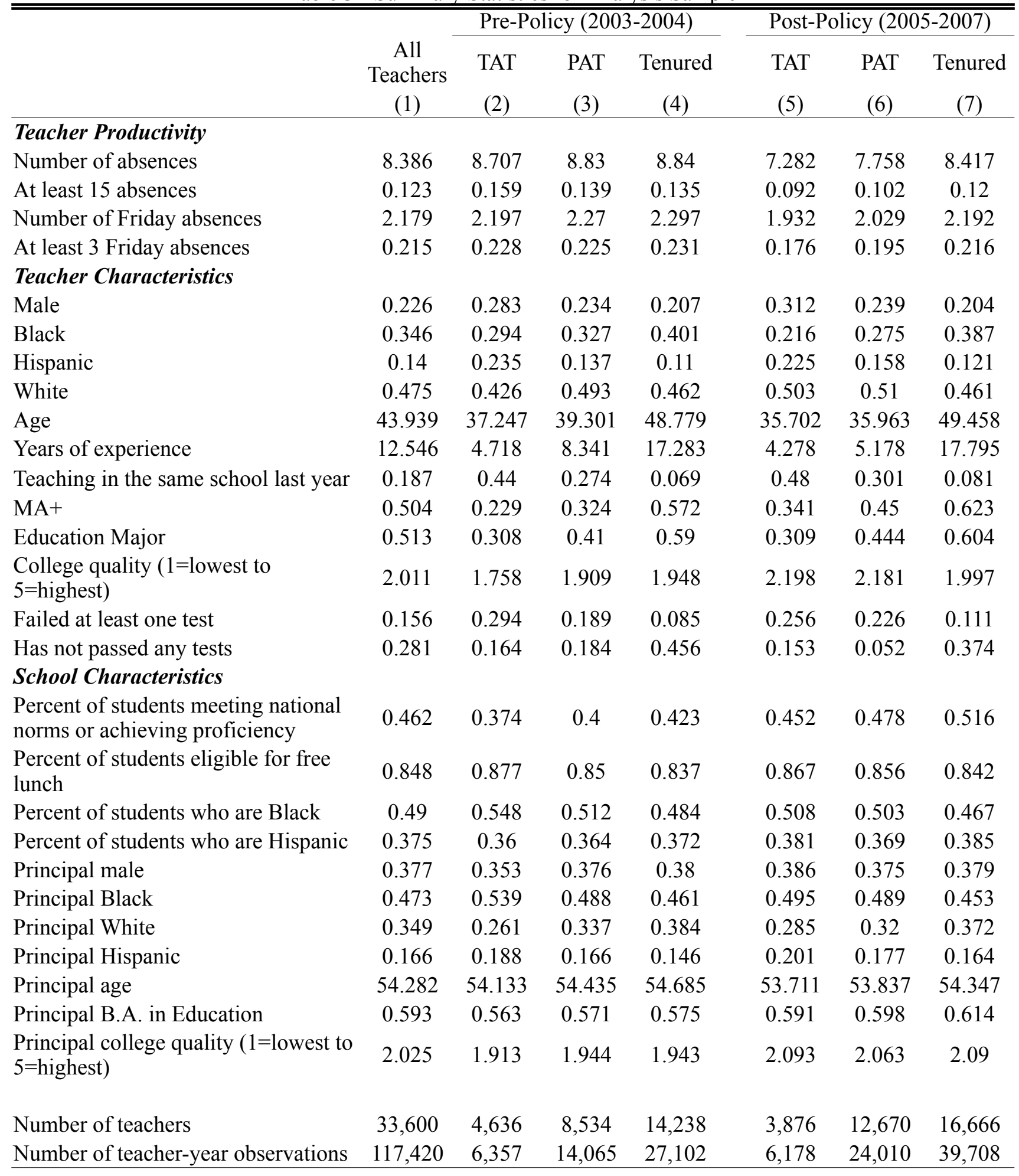




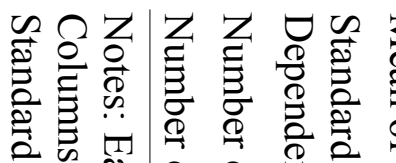

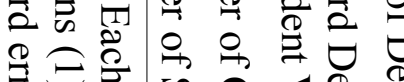

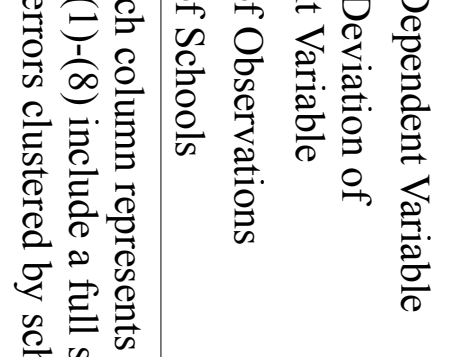

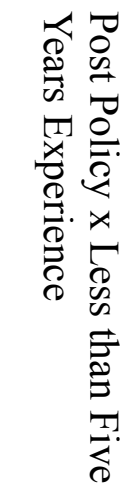

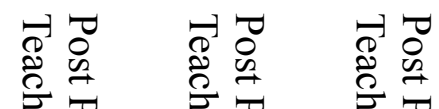

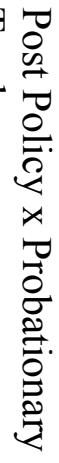

₹ั

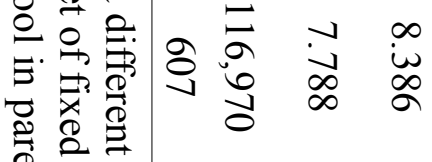

$\stackrel{0}{0} \overrightarrow{0}$

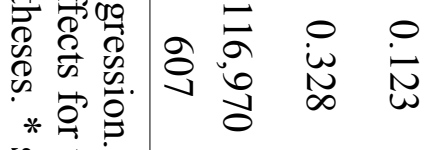

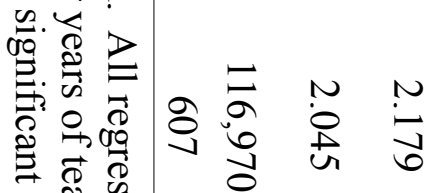

$\nRightarrow$ है

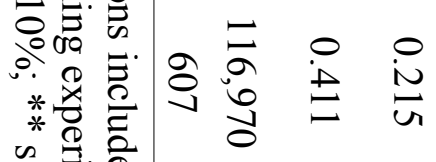

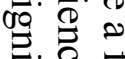

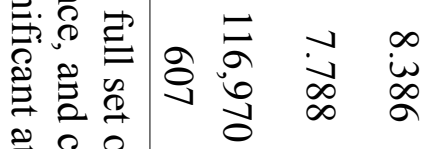
$\stackrel{2}{\circ} 0$

棺范

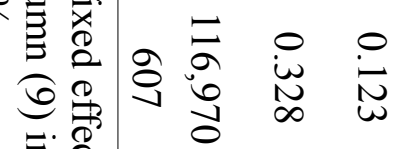

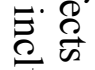

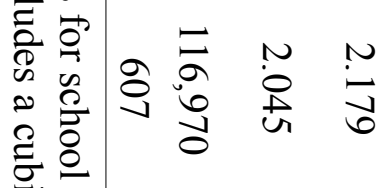

ก. 范

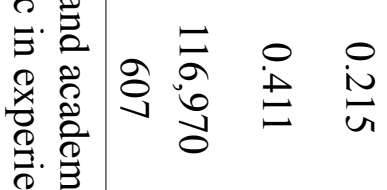

$\begin{array}{ll}\hat{0} & \dot{0} \\ \dot{0} & \infty \\ \stackrel{0}{0} & \stackrel{*}{*} \\ & *\end{array}$

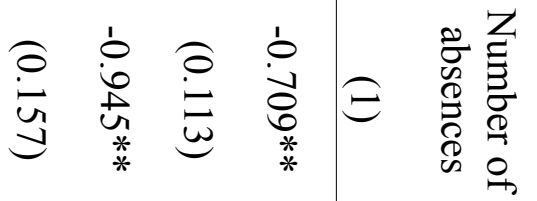

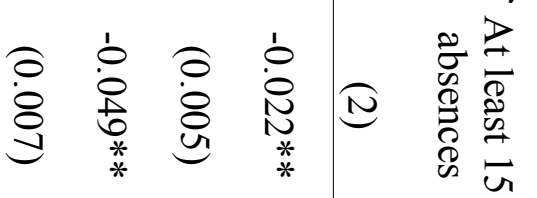

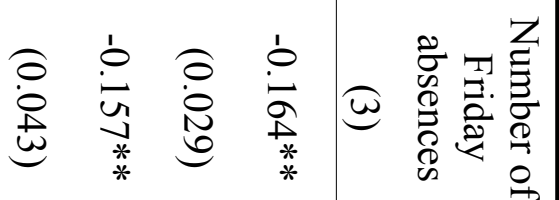

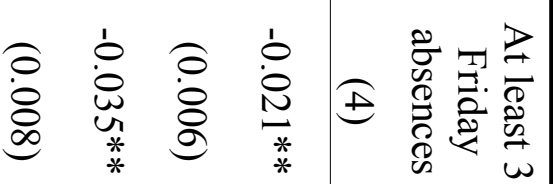

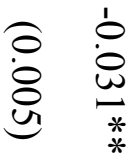

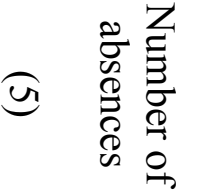

() $\quad \begin{gathered}\tilde{D} \\ 0\end{gathered}$

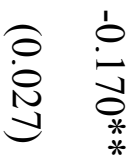

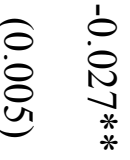

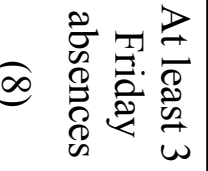

ล

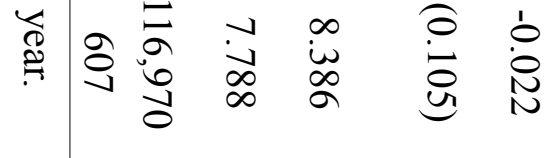

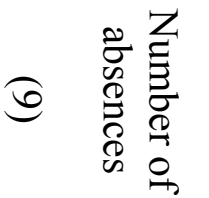


Table 5 - Robustness

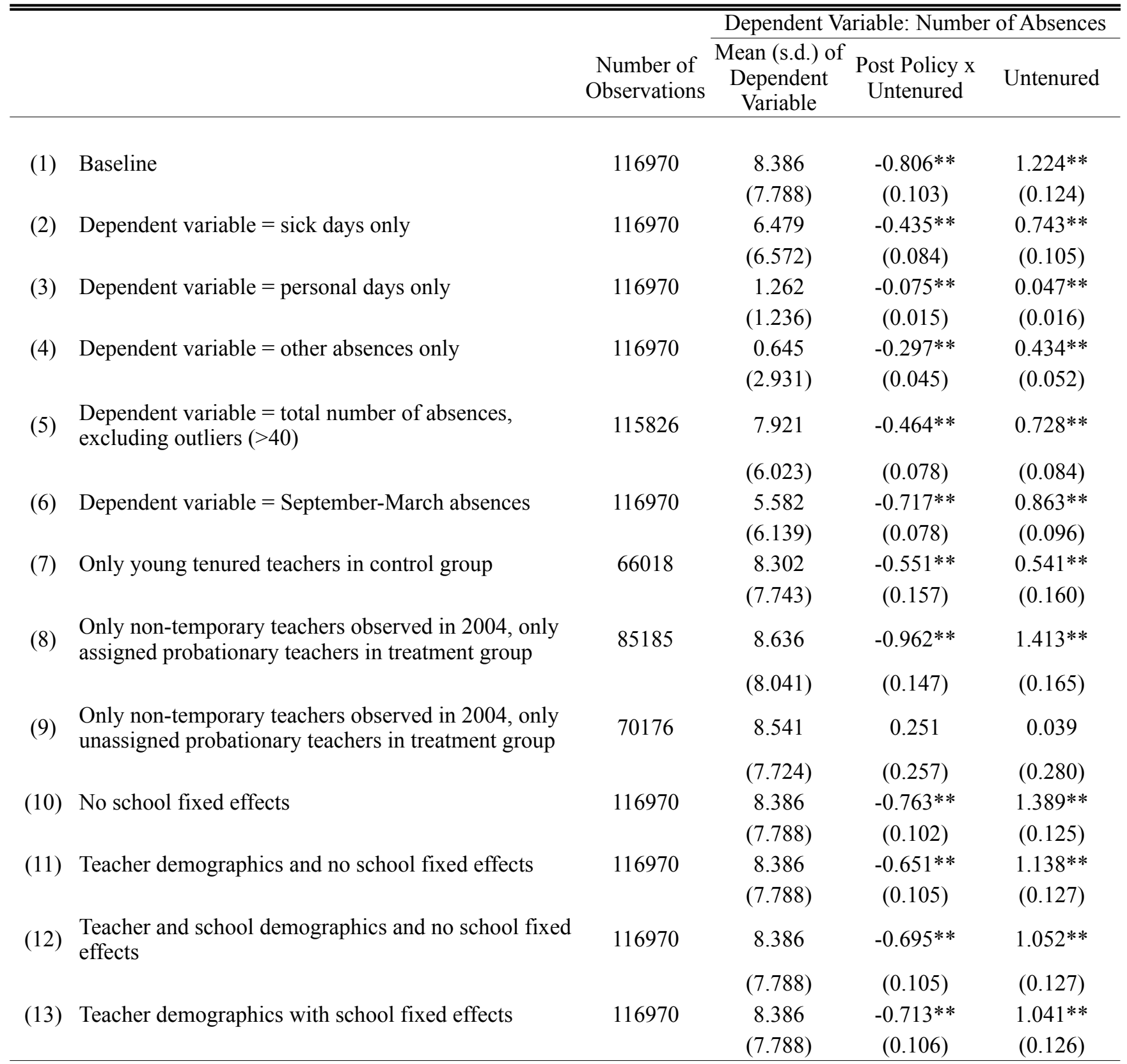

Notes: Each row represents a different regression. Regressions include school fixed effects, except where indicated otherwise. All regressions include a full set of fixed effects for academic year and years of teaching experience. Regressions with teacher demographics include race and gender dummies, race $\mathrm{x}$ gender interactions, teacher educational background controls, instructional program indicators, a cubic in age, and gender $\mathrm{x}$ age interactions. Regressions with school demographics include student race proportion variables, a cubic in school achievement, a cubic in school enrollment, an indicator for magnet schools, and an indicator for having multiple schools housed in the same building. Standard errors clustered by school in parentheses. * significant at 10\%; ** significant at 5\%. 


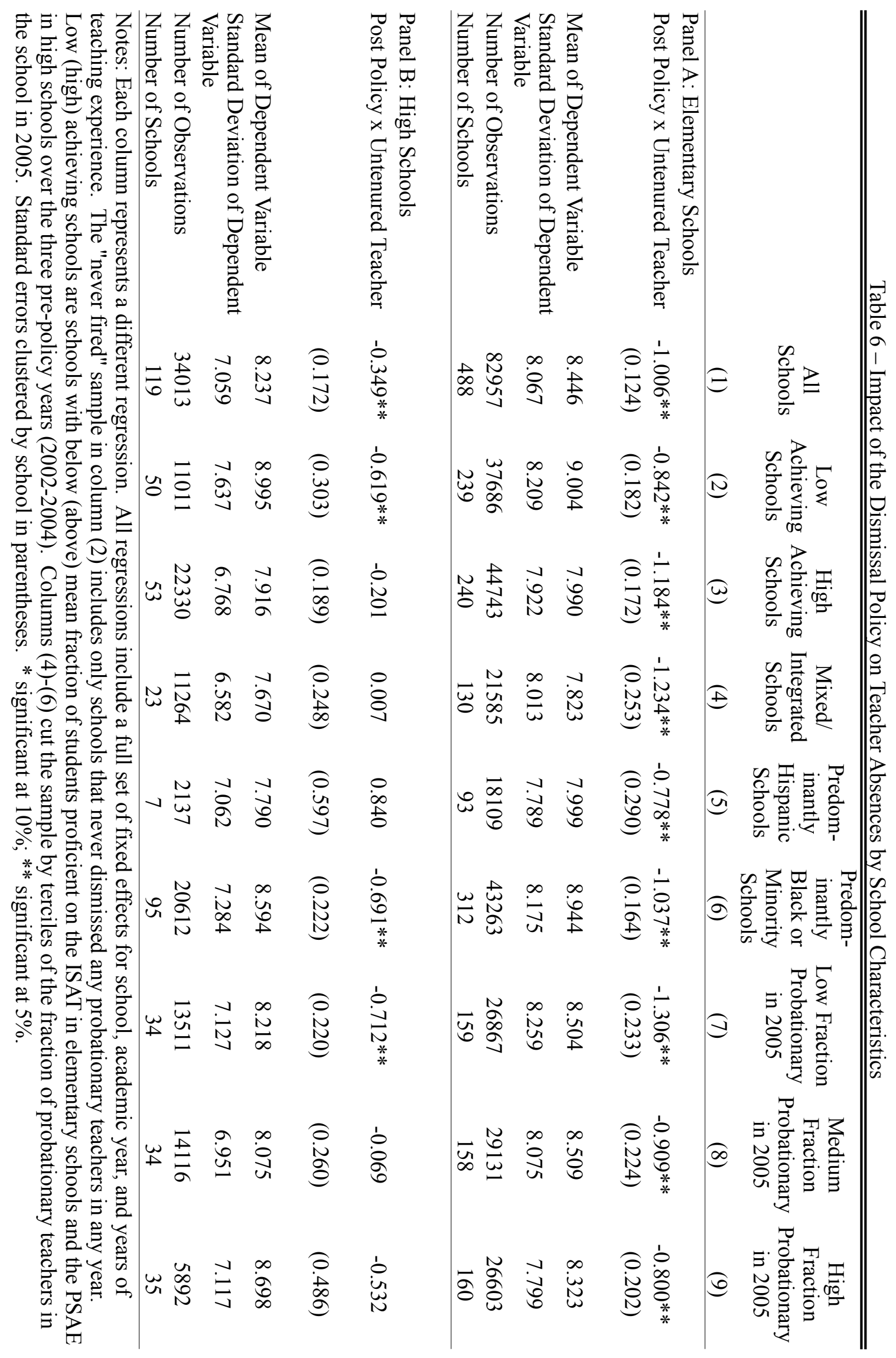




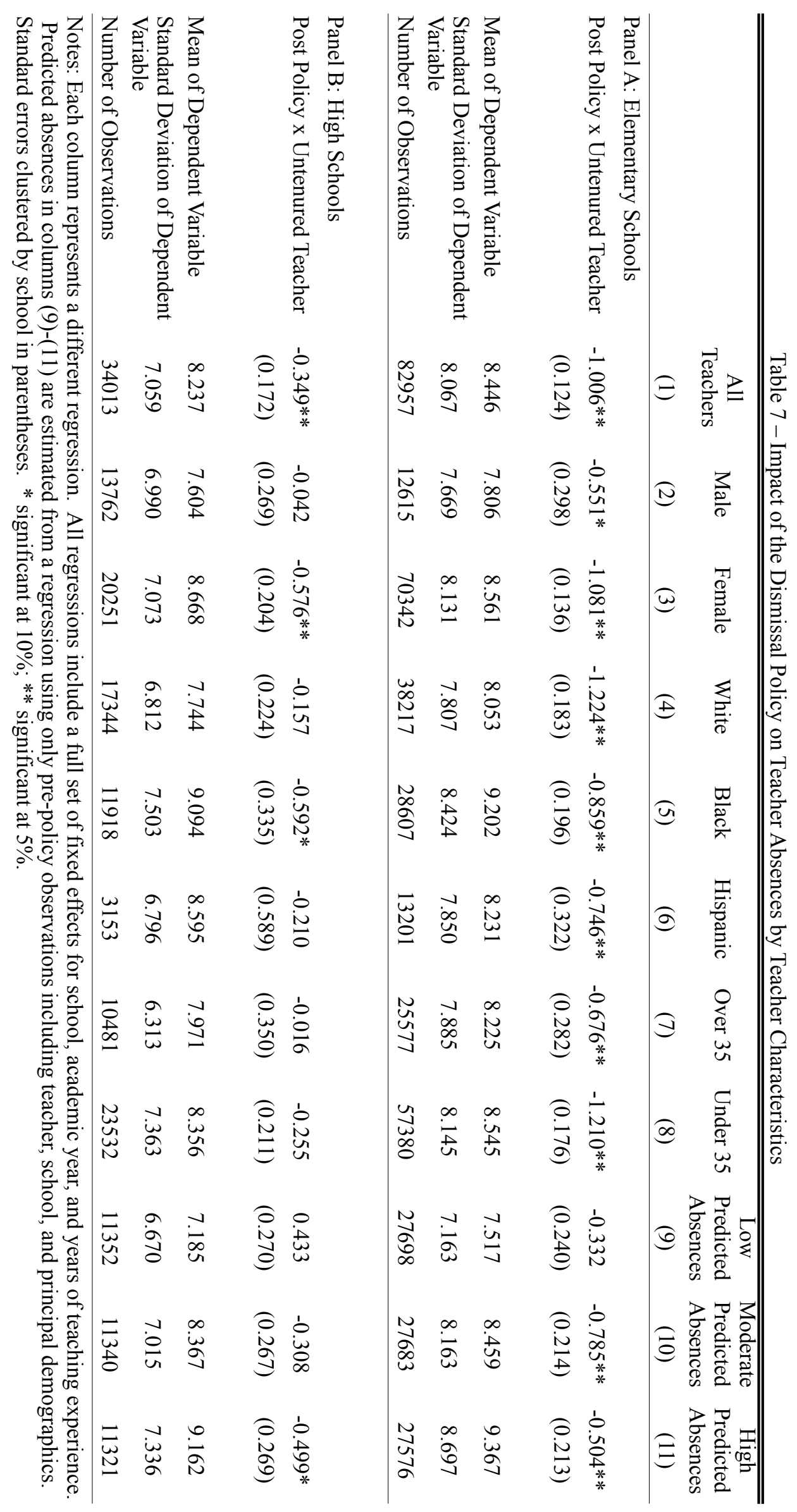


Table 8 - Impact of the Dismissal Policy by Predicted Probability of Dismissal

\begin{tabular}{|c|c|c|c|c|}
\hline & \multicolumn{4}{|c|}{ Dependent Variable: Number of Absences } \\
\hline & \multicolumn{4}{|c|}{ Quartile of Predicted Probability of Dismissal: } \\
\hline & Bottom & Second & Third & Top \\
\hline & $(1)$ & $(2)$ & $(3)$ & (4) \\
\hline \multicolumn{5}{|l|}{ Panel A: Elementary Schools } \\
\hline Post Policy x Untenured Teacher & $\begin{array}{c}-0.693 * * \\
(0.282)\end{array}$ & $\begin{array}{c}-0.879 * * \\
(0.257)\end{array}$ & $\begin{array}{c}-0.557 * * \\
(0.253)\end{array}$ & $\begin{array}{c}-1.089 * * \\
(0.305)\end{array}$ \\
\hline Mean of Dependent Variable & 8.904 & 8.490 & 8.254 & 8.311 \\
\hline Standard Deviation of Dependent Variable & 8.237 & 7.783 & 7.627 & 8.689 \\
\hline Number of Observations & 18562 & 18562 & 18559 & 18566 \\
\hline \multicolumn{5}{|l|}{ Panel B: High Schools } \\
\hline Post Policy x Untenured Teacher & $\begin{array}{l}-0.429 \\
(0.330)\end{array}$ & $\begin{array}{l}-0.498 \\
(0.358)\end{array}$ & $\begin{array}{l}-0.513 \\
(0.360)\end{array}$ & $\begin{array}{c}0.191 \\
(0.412)\end{array}$ \\
\hline Mean of Dependent Variable & 8.065 & 8.508 & 8.308 & 8.210 \\
\hline Standard Deviation of Dependent Variable & 6.319 & 7.031 & 6.963 & 7.986 \\
\hline Number of Observations & 7556 & 7556 & 7556 & 7556 \\
\hline
\end{tabular}

Notes: Each column represents a different regression. All regressions include a full set of fixed effects for school, academic year, and years of teaching experience. Standard errors clustered by school in parentheses. Predicted probability of dismissal is estimated from a conditional logit of dismissal on teacher demographics and teacher-school interactions conditional on school-year fixed effects (the fixed effects are not included in the prediction). All probationary teachers in 2005-2007 in school-years that dismissed at least one teacher are included in the conditional logit regression and probabilities of dismissal are predicted in and out of sample for all teachers. ${ }^{*}$ significant at $10 \%$; ** significant at $5 \%$. 
Table 9 - Effects by Calendar Year and Risk Year

\begin{tabular}{|c|c|c|c|}
\hline & \multicolumn{3}{|c|}{ Dependent Variable $=$ Number of Absences } \\
\hline & $\begin{array}{c}\text { Full sample } \\
\text { (1) }\end{array}$ & $\begin{array}{c}\text { Low } \\
\text { Achieving } \\
\text { Schools } \\
(2)\end{array}$ & $\begin{array}{c}\text { High } \\
\text { Achieving } \\
\text { Schools } \\
(3)\end{array}$ \\
\hline \multicolumn{4}{|l|}{ Panel A: Elementary Schools } \\
\hline Post Policy x Untenured Teacher & $\begin{array}{l}-0.713 * * \\
(0.151)\end{array}$ & $\begin{array}{l}-0.550 * * \\
(0.216)\end{array}$ & $\begin{array}{c}-0.863 * * \\
(0.214)\end{array}$ \\
\hline $\begin{array}{l}\text { Post Policy x Untenured Teacher } \mathrm{x} \\
\text { (Risk year } 2 \text { or } 3 \text { ) }\end{array}$ & $\begin{array}{l}0.238^{*} \\
(0.124)\end{array}$ & $\begin{array}{l}0.347^{*} \\
(0.181)\end{array}$ & $\begin{array}{l}0.177 \\
(0.173)\end{array}$ \\
\hline $\begin{array}{l}\text { Post Policy x Untenured Teacher x } \\
\text { (School year } 2006 \text { or 2007) }\end{array}$ & $\begin{array}{c}-0.489 * * \\
(0.148)\end{array}$ & $\begin{array}{l}-0.486 * * \\
(0.201)\end{array}$ & $\begin{array}{l}-0.548 * * \\
(0.215)\end{array}$ \\
\hline Mean of Dependent Variable & 8.446 & 9.004 & 7.990 \\
\hline $\begin{array}{l}\text { Standard Deviation of Dependent } \\
\text { Variable }\end{array}$ & 8.067 & 8.209 & 7.922 \\
\hline Number of Observations & 82957 & 37686 & 44743 \\
\hline Number of Schools & 488 & 239 & 240 \\
\hline \multicolumn{4}{|l|}{ Panel B: High Schools } \\
\hline Post Policy x Untenured Teacher & $\begin{array}{l}-0.169 \\
(0.209)\end{array}$ & $\begin{array}{l}-0.583 \\
(0.350)\end{array}$ & $\begin{array}{c}0.066 \\
(0.237)\end{array}$ \\
\hline \multirow[t]{2}{*}{$\begin{array}{l}\text { Post Policy x Untenured Teacher x } \\
\text { (Risk year } 2 \text { or } 3 \text { ) }\end{array}$} & 0.004 & -0.236 & 0.175 \\
\hline & $(0.182)$ & $(0.315)$ & $(0.227)$ \\
\hline \multirow[t]{2}{*}{$\begin{array}{l}\text { Post Policy x Untenured Teacher x } \\
\text { (School year } 2006 \text { or 2007) }\end{array}$} & -0.321 & 0.087 & $-0.579 * *$ \\
\hline & $(0.210)$ & $(0.386)$ & $(0.253)$ \\
\hline Mean of Dependent Variable & 8.237 & 8.995 & 7.916 \\
\hline $\begin{array}{l}\text { Standard Deviation of Dependent } \\
\text { Variable }\end{array}$ & 7.059 & 7.637 & 6.768 \\
\hline Number of Observations & 34013 & 11011 & 22330 \\
\hline Number of Schools & 119 & 50 & 53 \\
\hline \multicolumn{4}{|c|}{$\begin{array}{l}\text { Notes: Each column represents a different regression. All regressions include a full } \\
\text { set of fixed effects for school, academic year, and years of teaching experience. } \\
\text { Low (high) achieving schools are schools with below (above) mean fraction of } \\
\text { students proficient on the ISAT in elementary schools and the PSAE in high schools } \\
\text { over the three pre-policy years }(2002-2004) \text {. Standard errors clustered by school in } \\
\text { parentheses. } * \text { significant at } 10 \% ; * \text { significant at } 5 \% \text {. }\end{array}$} \\
\hline
\end{tabular}


Table 10 - Impact of the Dismissal Policy on School Level Student Achievement in Elementary Schools

\begin{tabular}{|c|c|c|c|c|c|c|}
\hline & \multicolumn{3}{|c|}{$\begin{array}{l}\text { At Risk of Dismissal }= \\
\text { Probationary Teachers }\end{array}$} & \multicolumn{3}{|c|}{$\begin{array}{l}\text { At Risk of Dismissal = } \\
\text { Untenured Teachers }\end{array}$} \\
\hline & $\begin{array}{l}\text { All } \\
(1)\end{array}$ & $\begin{array}{c}\text { Low } \\
\text { Achieving } \\
\text { Schools } \\
(2)\end{array}$ & $\begin{array}{c}\text { High } \\
\text { Achieving } \\
\text { Schools } \\
(3)\end{array}$ & $\begin{array}{l}\text { All } \\
\text { (4) } \\
\end{array}$ & $\begin{array}{c}\text { Low } \\
\text { Achieving } \\
\text { Schools } \\
(5)\end{array}$ & $\begin{array}{c}\text { High } \\
\text { Achieving } \\
\text { Schools } \\
(6)\end{array}$ \\
\hline \multicolumn{7}{|c|}{ Dependent Variable = Math Scaled Scores } \\
\hline \multirow{2}{*}{$\begin{array}{l}\text { Post Policy x Fraction Teachers at } \\
\text { Risk of Dismissal in } 2005\end{array}$} & 0.127 & 0.160 & 0.081 & 0.195 & $0.241^{*}$ & 0.121 \\
\hline & $(0.132)$ & $(0.157)$ & $(0.210)$ & $(0.119)$ & $(0.140)$ & $(0.192)$ \\
\hline Mean of Dependent Variable & 0.042 & -0.666 & 0.719 & 0.042 & -0.666 & 0.719 \\
\hline \multicolumn{7}{|c|}{ Dependent Variable $=$ Math Fraction Proficient } \\
\hline \multirow{2}{*}{$\begin{array}{l}\text { Post Policy x Fraction Teachers at } \\
\text { Risk of Dismissal in } 2005\end{array}$} & 0.022 & 0.041 & -0.007 & $0.051^{*}$ & $0.080 * *$ & 0.009 \\
\hline & $(0.034)$ & $(0.041)$ & $(0.049)$ & $(0.030)$ & $(0.037)$ & $(0.044)$ \\
\hline Mean of Dependent Variable & 0.540 & 0.394 & 0.680 & 0.540 & 0.394 & 0.680 \\
\hline \multicolumn{7}{|c|}{ Dependent Variable $=$ Reading Scaled Scores } \\
\hline \multirow[t]{2}{*}{$\begin{array}{l}\text { Post Policy x Fraction Teachers at } \\
\text { Risk of Dismissal in } 2005\end{array}$} & 0.119 & $0.277^{*}$ & -0.064 & 0.181 & $0.316^{* *}$ & 0.020 \\
\hline & $(0.124)$ & $(0.166)$ & $(0.165)$ & $(0.111)$ & $(0.143)$ & $(0.151)$ \\
\hline Mean of Dependent Variable & 0.046 & -0.669 & 0.730 & 0.046 & -0.669 & 0.730 \\
\hline \multicolumn{7}{|c|}{ Dependent Variable $=$ Reading Fraction Proficient } \\
\hline \multirow{2}{*}{$\begin{array}{l}\text { Post Policy x Fraction Teachers at } \\
\text { Risk of Dismissal in } 2005\end{array}$} & 0.037 & 0.046 & 0.019 & $0.052 * *$ & $0.066^{* *}$ & 0.028 \\
\hline & $(0.028)$ & $(0.038)$ & $(0.036)$ & $(0.024)$ & $(0.033)$ & $(0.032)$ \\
\hline Mean of Dependent Variable & 0.514 & 0.388 & 0.635 & 0.514 & 0.388 & 0.635 \\
\hline \multicolumn{7}{|c|}{$\begin{array}{l}\text { Notes: Each cell represents a different school-year level regression with the indicated dependent variable. } \\
\text { Standard errors clustered by school in parentheses. The elementary school assessment is the math and } \\
\text { reading ISAT taken in grades } 3,5 \text {, and } 8 \text {. Scaled scores are standardized at the school level within grade- } \\
\text { subject-year to a mean of } 0 \text { and a standard deviation of } 1 \text {. All assessment outcomes represent an enrollment } \\
\text { weighted average across grades within school-year. All regressions include controls for the fraction of low } \\
\text { income students in the school year, fraction of low income students x post policy, mean level of teaching } \\
\text { experience in the school-year, mean experience squared, the fraction of first or second year teachers in the } \\
\text { school-year, other school demographics, indicators for whether the assessment is observed in each grade, the } \\
\text { fraction of enrolled students in the grade taking the exam, and a full set of fixed effects for school and } \\
\text { academic year. Low (high) achieving schools are schools with below (above) mean fraction of students } \\
\text { proficient on the ISAT over the three pre-policy years }(2002-2004) \text {. For elementary schools, the mean within } \\
\text { school percent probationary (untenured) teachers in } 2005 \text { was } 33 \%(43 \%) \text {, the } 90^{\text {th }} \text { percentile was } 50 \%(65 \%) \\
\text { and the } 10^{\text {th }} \text { percentile was } 19 \%(26 \%) \text {. * significant at } 10 \% \text {; } * * \text { significant at } 5 \% \text {. }\end{array}$} \\
\hline
\end{tabular}

